\title{
Lipocalin 2 modulates the cellular response to amyloid beta
}

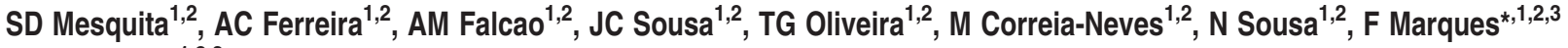 \\ and JA Palha ${ }^{1,2,3}$
}

The production, accumulation and aggregation of amyloid beta $(A \beta)$ peptides in Alzheimer's disease (AD) are influenced by different modulators. Among these are iron and iron-related proteins, given their ability to modulate the expression of the amyloid precursor protein and to drive $A \beta$ aggregation. Herein, we describe that lipocalin 2 (LCN2), a mammalian acute-phase protein involved in iron homeostasis, is highly produced in response to $A \beta_{1-42}$ by choroid plexus epithelial cells and astrocytes, but not by microglia or neurons. Although $A \beta_{1-42}$ stimulation decreases the dehydrogenase activity and survival of wild-type astrocytes, astrocytes lacking the expression of $L c n 2$ are not affected. This protection results from a lower expression of the proapoptotic gene Bim and a decreased inflammatory response. Altogether, these findings show that A $\beta$ toxicity to astrocytes requires $L C N 2$, which represents a novel mechanism to target when addressing $A D$.

Cell Death and Differentiation (2014) 21, 1588-1599; doi:10.1038/cdd.2014.68; published online 23 May 2014

One of the pathological hallmarks of Alzheimer's disease (AD) is the increased production and accumulation of amyloid beta $(\mathrm{A} \beta)$ peptides in the brain, which result from the misprocessing of the membrane amyloid precursor protein. Through an unidentified combination of events, $\mathrm{A} \beta$ peptides, initially soluble, aggregate into oligomers, which are highly toxic to brain cells. Oligomers of $A \beta$ ultimately deposit in different brain regions and form amyloid plaques. ${ }^{1}$ The steps that drive the amyloidogenic pathway are still unclear, but the aggregation of $A \beta$ into dimers, trimers and other toxic oligomeric forms seems to be decisive. This process was shown to be influenced by many factors, among which is iron, described to favor the formation and stabilization of toxic $A \beta$ oligomers. ${ }^{2,3}$ Notably, iron accumulates with age in brain areas that are preferentially affected in AD patients, such as the hippocampus and the cortex. ${ }^{4}$ In these areas, iron and ironbinding proteins were shown to accumulate in the amyloid plaques. ${ }^{5}$ Interestingly, recent evidence points to alterations in the level of iron metabolism-related proteins, such as ferritin, and their impact on iron homeostasis as probable causes of increased amyloid precursor protein expression and misprocessing, as well as increased aggregation of $A \beta$ into toxic oligomers. 6,7

Recently, the iron-associated protein lipocalin 2 (LCN2) was implicated in AD. ${ }^{8}$ LCN2, a member of the lipocalin family of soluble proteins, was originally identified as a constituent of granules in human neutrophils. ${ }^{9}$ It was first described as an acute-phase protein ${ }^{10}$ able to bind and sequester bacterial iron-loaded siderophores, thus preventing the growth and dissemination of the infectious agents. ${ }^{11}$ In addition, LCN2 has been described also to mediate transferrin-independent iron delivery ${ }^{12,13}$ and removal from cells, ${ }^{14}$ which is associated with cell proliferation and apoptosis, respectively. Although the pathway through which LCN2 influences cell proliferation remains uncertain, LCN2-mediated apoptosis involves the proapoptotic protein BCL2-like 11 (BCL2L11 or BIM). ${ }^{14,15}$ Of notice, different cells from the central nervous system (CNS), namely choroid plexus (CP) epithelial cells and astrocytes, have been shown to produce LCN2 in response to various stimuli. ${ }^{15-19}$ Importantly, a recent study demonstrated that LCN2, produced in response to tumor necrosis factor (TNF), is able to interfere with TNF receptor protective signaling and to enhance the toxicity of glutamate and $\mathrm{A} \beta{ }^{8}$ The present study investigated the mechanism through which LCN2 contributes to the modulation of brain cell metabolism and survival in response to $\mathrm{A} \beta$.

\section{Results}

CP epithelial cells overexpress Lcn2 in response to $\mathbf{A} \boldsymbol{\beta}_{1-42}$. Incubation of rat $C P$ epithelial cells with $A \beta_{1-42}$ induced the expression of $L c n 2$, specifically $48 \mathrm{~h}$ after incubation with $1 \mu \mathrm{M} \quad \mathrm{A} \beta_{1-42}$. Incubation with a lower concentration of $\mathrm{A} \beta_{1-42}, 0.1 \mu \mathrm{M}$, for 24 and $48 \mathrm{~h}$ did not influence the expression of $L c n 2$ (Figure 1a). The expression of the genes encoding for the receptors of LCN2 (the solute

\footnotetext{
${ }^{1}$ Life and Health Sciences Research Institute (ICVS), School of Health Sciences, University of Minho, Campus Gualtar, 4710-057 Braga, Portugal and ${ }^{2}$ ICVS/3B's-PT Government Associate Laboratory, Guimaraes, Portugal

${ }^{*}$ Corresponding author: F Marques, Life and Health Sciences Research Institute (ICVS), School of Health Sciences, University of Minho, Campus Gualtar, $4710-057$ Braga, Portugal. Tel: +351 253 604839; Fax: +351 253 604809; E-mail: fmarques@ecsaude.uminho.pt

${ }^{3}$ These authors share co-authorship.

Abbreviations: $\mathrm{A} \beta$, amyloid beta; AD, Alzheimer's disease; $\beta$ III-TUB, $\beta$ III-tubulin; BIM, BCL2-like 11 ; CNS, central nervous system; CP, choroid plexus; CSF, cerebrospinal fluid; Cxcl10, chemokine (C-X-C motif) ligand 10; Fth, ferritin heavy chain; GFAP, glial fibrillary acidic protein; IL-6/12/23, interleukin-6/-12/-23; Hmox1/2, heme oxygenase 1/2; LCN2, lipocalin 2; LPS, lipopolysaccharide; Lrp2, low density lipoprotein-related protein 2; MitoT, MitoTracker Red FM; SIc22a17 or 24p3r, solute carrier family 22 member 17; TNF, tumor necrosis factor; TTR, transthyretin

Received 29.10.13; revised 07.4.14; accepted 15.4.14; Edited by L Greene; published online 23.5.14
} 

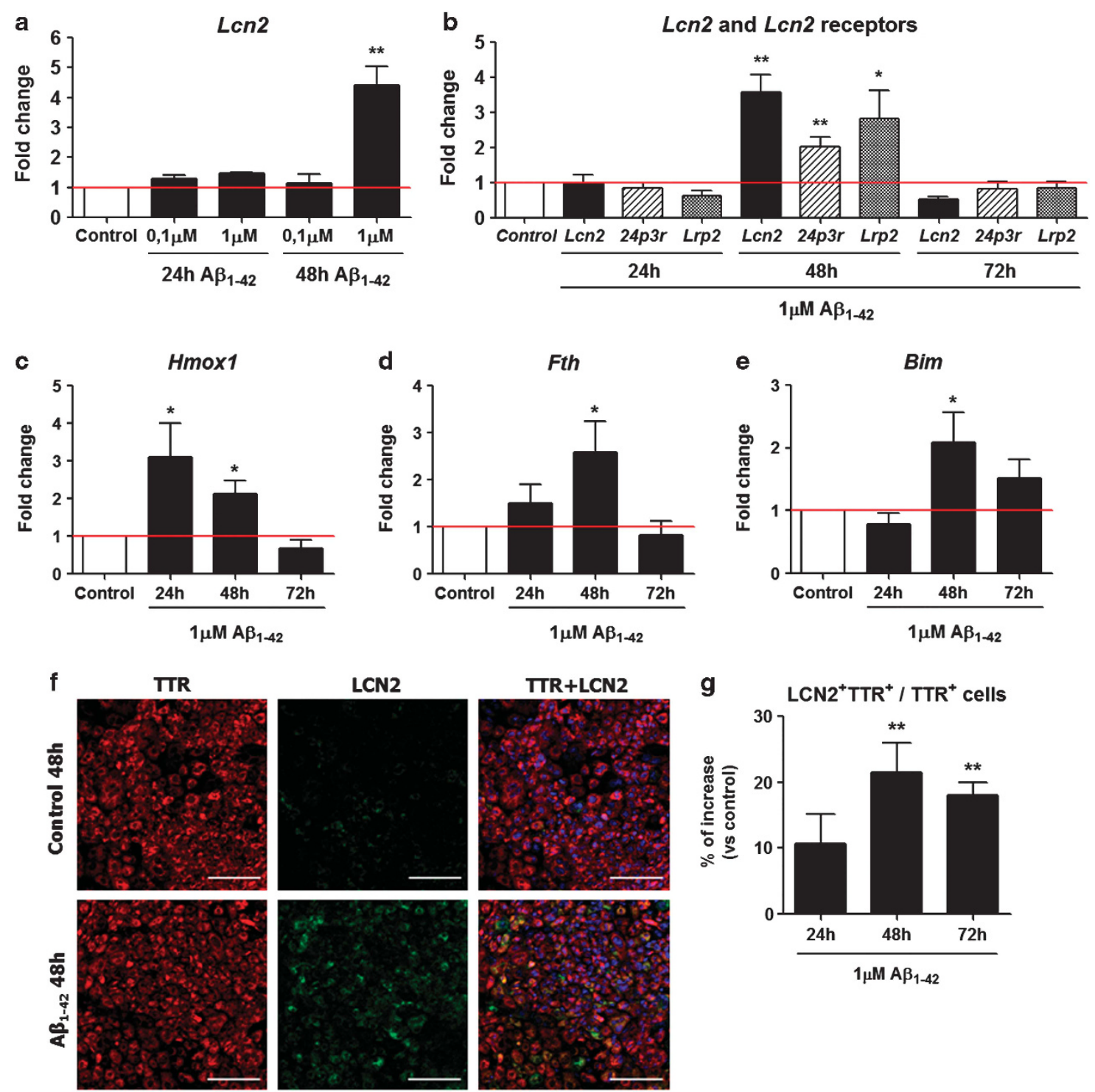

Figure $1 C P$ epithelial cells express $L c n 2$ in response to $A \beta_{1-42 .}$. (a) $L c n 2 m R N A$ level was measured in cultures of rat $C P$ epithelial cells at 24 and $48 \mathrm{~h}$ after incubation with vehicle (control, red line) or different dosages of $A \beta_{1-42}(0.1$ or $1 \mu \mathrm{M})$. Lcn2 expression was significantly increased only with $1 \mu \mathrm{M} \mathrm{A} \beta_{1-42}$ at $48 \mathrm{~h}$. (b) The expression of $L c n 2$ and of the genes that encode for its receptors (24p3r and $L r p 2)$ was found significantly upregulated at $48 \mathrm{~h}$ of incubation with $1 \mu \mathrm{M} \mathrm{A} \beta_{1-42}$ in comparison with the respective time-point controls. (c-e) The expression of $H \operatorname{mox} 1$ (c) was found significantly upregulated at $24 \mathrm{~h}$ of incubation with $1 \mu \mathrm{M} \mathrm{A} \beta_{1-42}$, whereas the expression of Fth (d) and Bim (e) was upregulated only at $48 \mathrm{~h}$. (f) CP epithelial cells were stained for DAPI (blue) and with antibodies for TTR (red) and LCN2 (green). A clear increase in LCN2 production was observed in $A \beta_{1-42}$-treated cells. (g) The quantification of LCN2 ${ }^{+} \mathrm{TTR}^{+} \mathrm{CP}$ epithelial cells revealed that after treatment with $\mathrm{A} \beta_{1-42}$ for 48 and $72 \mathrm{~h}$ there was a significant increase in the percentage of double-positive cells, when compared with the respective time-point controls. Results are presented as mean \pm S.E.M. ( $N \geq 4 / g r o u p ; ~ a-g)$ and are representative of three independent experiments. Scale bars $=100 \mu \mathrm{m} .{ }^{\star} P<0.05$ and ${ }^{\star \star} P<0.01$ versus control; ANOVA with Tukey's multiple comparison test

carrier family 22 member 17 (S/c22a17 or 24p3r) and the low-density lipoprotein-related protein 2 (Lrp2); Figure 1b), for the iron metabolism-related proteins, heme oxygenase 1 (Hmox1) and ferritin heavy chain 1 (Fth), as well as the expression of the proapoptotic gene Bim (Figures 1c-e) was also induced by $1 \mu \mathrm{M} \mathrm{A} \beta_{1-42}$. The alteration in Lcn2 expression resulted in increased percentage of cells co-expressing LCN2 and transthyretin (TTR), a CP epithelial cell-specific marker (Figures if and g).

Astrocytes produce and secrete LCN2 in response to $\mathbf{A} \boldsymbol{\beta}_{1-42}$. As early as $24 \mathrm{~h}$ after incubation with $1 \mu \mathrm{M} \mathrm{A} \beta_{1-42}$, cultured astrocytes isolated from rat brain cortex, which were $\geq 95 \%$ positive for the specific astrocyte marker glial fibrillary acidic protein (GFAP), presented an overexpression of Lcn2, and of its receptors, $24 p 3 r$ and Lrp2 (Figure 2a). Notably, accompanying the upregulation in gene expression, an increased oligomerization of $\mathrm{A} \beta_{1-42}$ was observed from $24 \mathrm{~h}$ onwards (Supplementary Figure 1). Double staining for GFAP and LCN2 (Figure 2b) and for CD11b, a specific marker for microglia present in these cultures, and LCN2 (Figure 2c) showed intracellular LCN2 labeling in GFAP ${ }^{+}$cells, but not in $\mathrm{CD}_{11} \mathrm{~b}^{+}$cells, upon $\mathrm{A} \beta_{1-42}$ stimulation. In accordance, the percentage of 


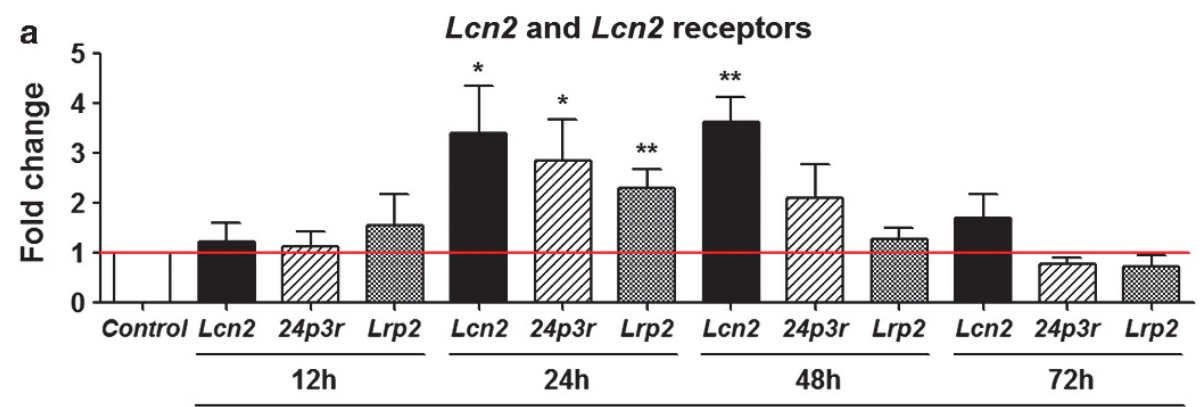

$1 \mu \mathrm{MA} \beta_{1-42}$

b
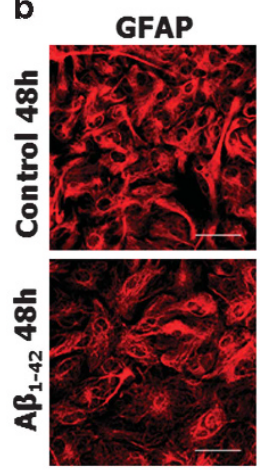

d
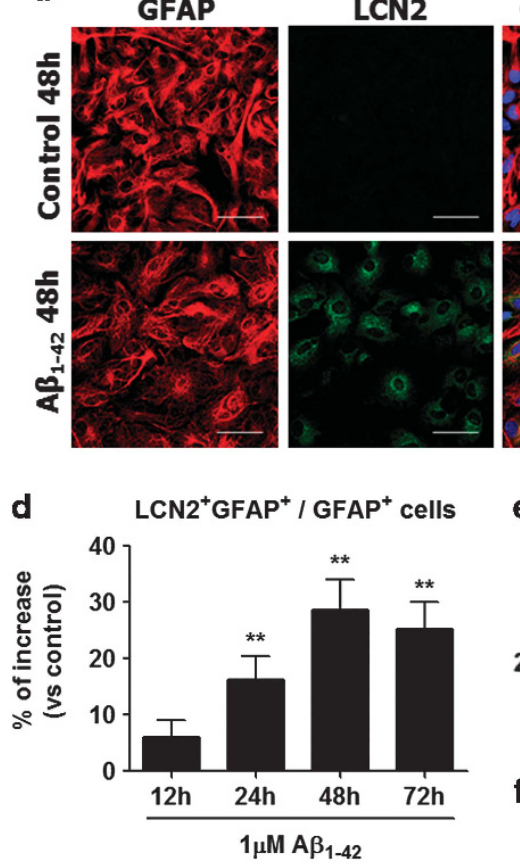

GFAP+LCN2
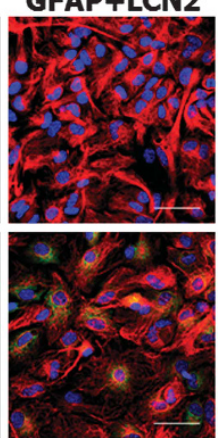

e
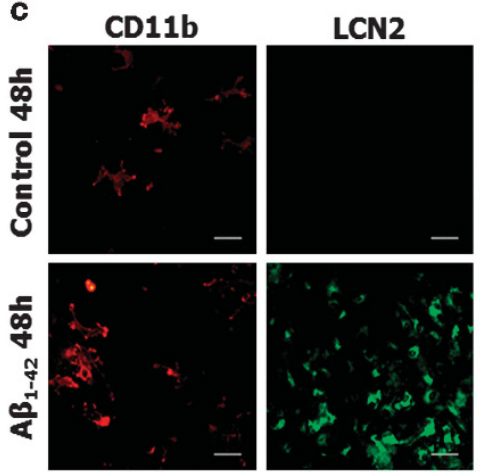

Astrocyte culture medium

Co $A \beta_{142} A \beta_{142}$ Co $A \beta_{142} A \beta_{142}$ Co $A \beta_{142} A \beta_{142}$

$25 \mathrm{kDa}-$

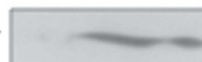

LCN2 (24 kDa)

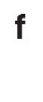

Astrocyte culture medium

$\frac{\operatorname{Len} 2(+/+)}{\text { Co Co } A \beta_{142} A \beta_{142} \text { LPS }} \frac{\operatorname{Len} 2(-/-)}{\text { Co } A \beta_{142} \text { LPS }}$

$25 \mathrm{kDa}-$

Co Co $A \beta_{142} A \beta_{142}$ LPS

Co $A \beta_{142}$ LPS

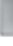

Figure 2 LCN2 is produced by cultured astrocytes in response to $A \beta_{1-42}$. (a) Lcn2, 24p3r and Lrp2 expression levels were measured in astrocytes cultured with $1 \mu \mathrm{M} A \beta_{1-42}$ for $12,24,48$ or $72 \mathrm{~h}$ and compared with the respective time-point controls (red line). Gene expression was significantly increased $24 \mathrm{~h}$ after the incubation with $1 \mu \mathrm{M} \mathrm{A} \beta_{1-42}$ and presented a progressive decrease until it reached control levels at $72 \mathrm{~h}$. (b) Astrocytes treated with vehicle (control) or with $1 \mu \mathrm{M} \mathrm{A} \beta_{1-42}$ for $48 \mathrm{~h}$ were stained for DAPI (blue) and with antibodies for GFAP (red) and LCN2 (green). (c) Microglia, found in the astrocyte-enriched cultures, stained positively for the specific marker CD11b (red), but not for LCN2 (green). (d) A significant increase in the percentage of LCN2 ${ }^{+} \mathrm{GFAP}^{+}$astrocytes was observed after treatment with $\mathrm{A} \beta_{1-42}$ for 24,48 and $72 \mathrm{~h}$, when compared with the respective time-point controls. (e) LCN2 protein was found to be increased in the culture supernatant of $L c n 2(+I+)$ astrocytes 24,48 and $72 \mathrm{~h}$ after incubation with $1 \mu \mathrm{M} \mathrm{A} \beta_{1-42}$, when compared with the supernatant of vehicle-treated LCn2( $+/+$ ) astrocytes (Co). (f) LCN2 protein was secreted by Lcn2( $\left.+/+\right)$ astrocytes in response to incubation with $1 \mu \mathrm{M} \mathrm{A} \beta_{1-42}$ or with $100 \mathrm{ng} / \mathrm{ml}$ LPS, whereas no LCN2 was detected in the supernatant of $L c n 2(-/-)$ astrocytes. Results are presented as mean \pm S.E.M. $(\mathrm{N} \geq 4 /$ group; $\mathbf{a}$ and $\mathbf{d})$ and are representative of two (b-f) or three (a) independent experiments. Scale bars $=25 \mu \mathrm{m} .{ }^{*} P<0.05$ and ${ }^{* *} P<0.01$ versus control; ANOVA with Tukey's multiple comparison test

$\mathrm{LCN}_{2}{ }^{+} \mathrm{GFAP}^{+}$cells significantly increased, reaching a peak at $48 \mathrm{~h}$ (Figure 2d), as well as the amount of LCN2 secreted by these cells (Figure 2e). LCN2 was secreted by astrocytes both in response to $A \beta_{1-42}$ and to bacterial lipopolysaccharide (LPS), a well-known inducer of the expression of $L c n 2^{18}$ that was used as control (Figure 2f). Of notice, when $A \beta_{1-42}$ was used to stimulate microgliaenriched cultures, no LCN2 production was observed (data not shown).
Treatment with $1 \mu \mathrm{M} \mathrm{A} \beta_{1-42}$ did not influence the expression of $L c n 2$ in neuronal-enriched primary cultures from the mouse brain (Figure 3a); whereas a significant overexpression of 24p3rand a decreased expression of Lrp2 was observed after incubating neurons with $A \beta_{1-42}$ for $48 \mathrm{~h}$ (Figure 3a). Western blot quantification of protein extracts from cultured mouse astrocytes or neurons exposed to $A \beta_{1-42}$ for 48 and $72 \mathrm{~h}$ showed that LCN2 is highly produced by astrocytes but not by neurons (Figure $3 b)$. Using beta III-tubulin ( $\beta$ III-TUB) as a 

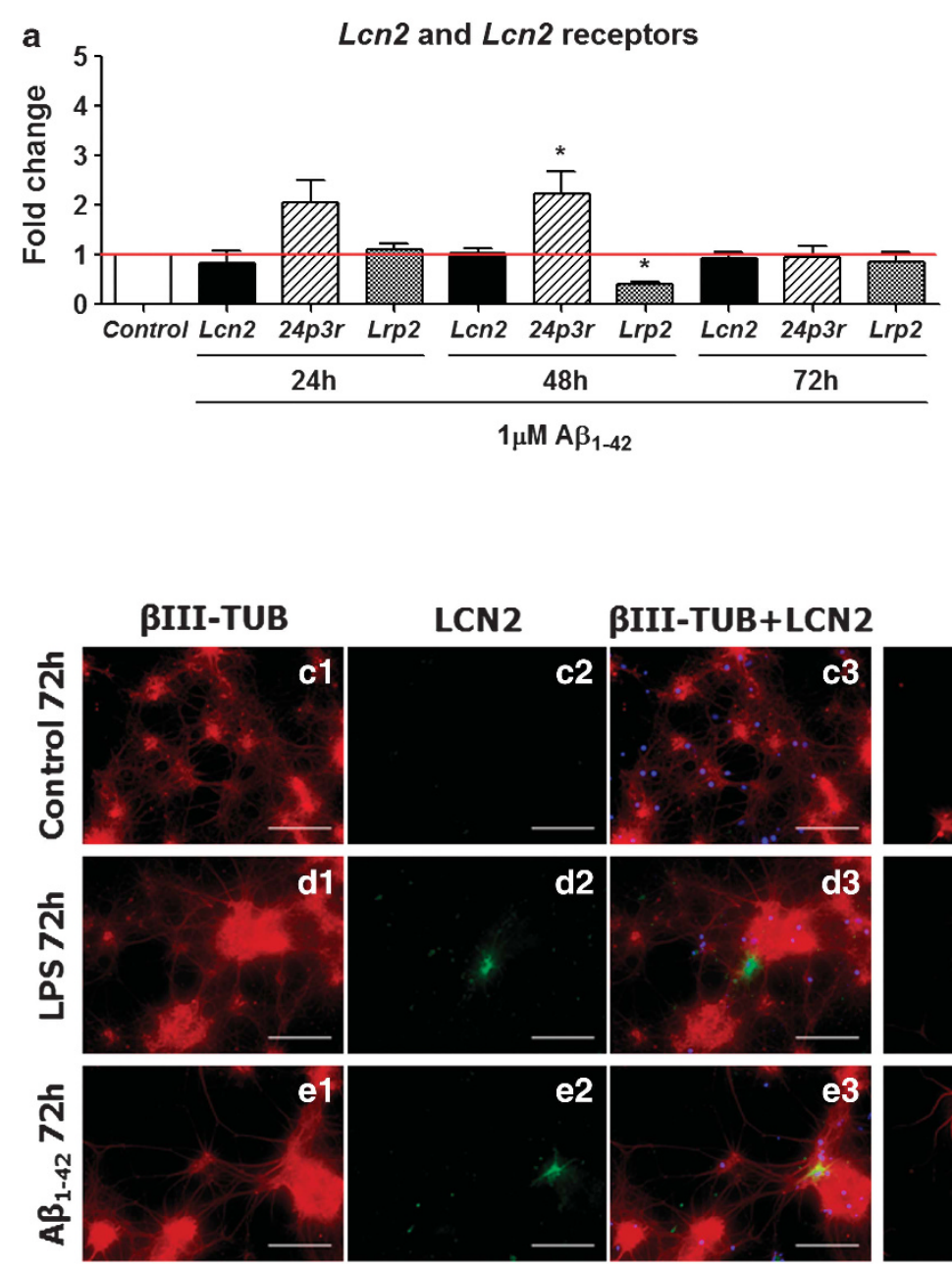

b

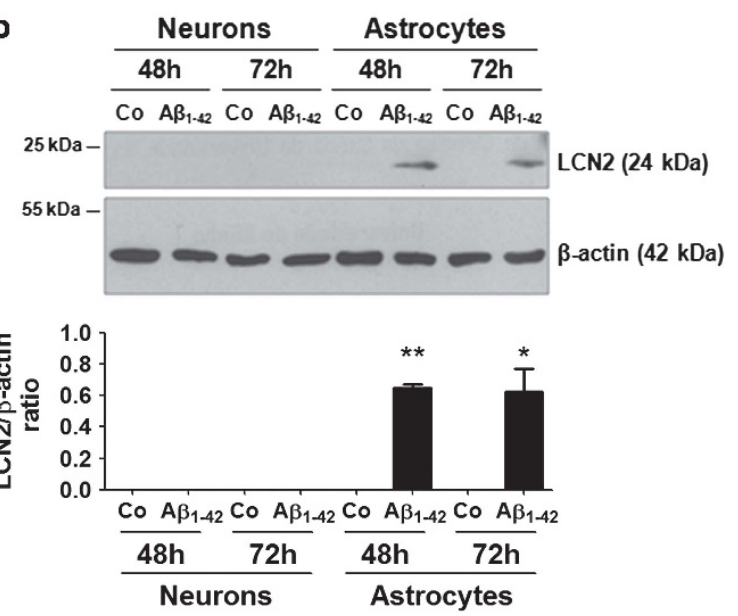

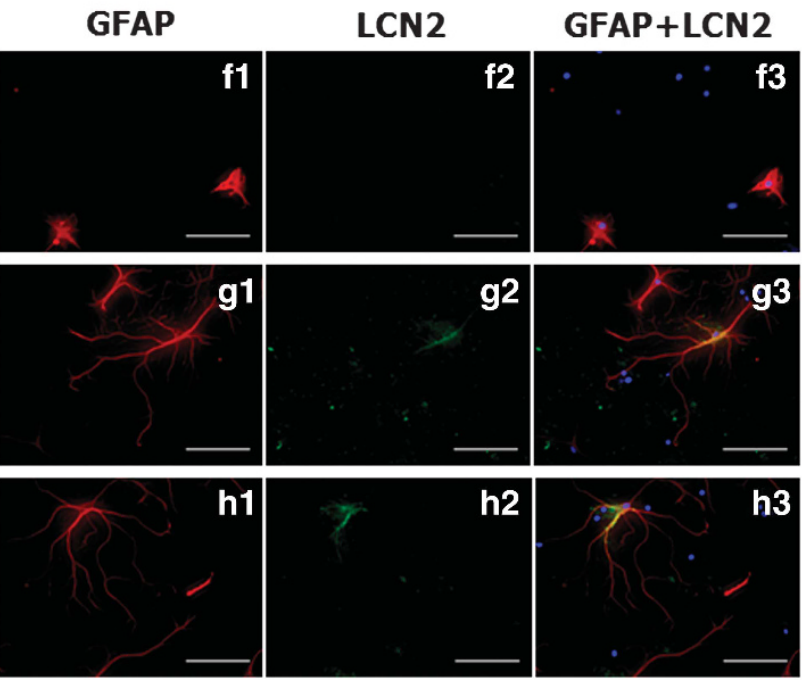

Figure 3 Neurons do not produce $L C N 2$ in response to $A \beta_{1-42 .}$ (a) $L c n 2,24 p 3 r$ and $L r p 2$ expression levels were measured in primary cultures of neurons isolated from P0-P1 mice cortices, treated with $1 \mu \mathrm{M} \mathrm{A} \beta_{1-42}$ for 24,48 or $72 \mathrm{~h}$ and compared with the respective time-point controls (red line). (b) Western blot analysis of protein extracts from cultured neurons or astrocytes treated with vehicle $(\mathrm{Co})$ or $\mathrm{A} \beta_{1-42}$ for 48 and $72 \mathrm{~h}$ showed that only astrocytes produce $\mathrm{LCN} 2$. The ratio between the intensity of the bands of LCN2 and $\beta$-actin confirmed the high levels of intracellular LCN2 only in astrocytes treated with $\mathrm{A} \beta_{1-42}$. (c-h) Cultured neurons were treated with vehicle (c and $\left.\mathbf{f}\right), 100 \mathrm{ng} / \mathrm{ml}$ LPS (d and $\mathbf{g}$ ) or $1 \mu \mathrm{M} \mathrm{A} \beta_{1-42}$ (e and $\mathbf{h}$ ) for $72 \mathrm{~h}$. Immunocytochemical staining using DAPI (blue) and specific antibodies for LCN2 (green) and $\beta \| 1 /$-TUB (c-e) or GFAP (f-h) (red) showed that only $<5 \%$ of total cells, specifically GFAP ${ }^{+}$astrocytes, were producing LCN2 in response to LPS and A $\beta_{1-42}$. Results are representative of two (a, c-h) or three (b) independent experiments. Scale bars $=50 \mu \mathrm{m}$. ${ }^{*} P<0.05$ and ${ }^{* *} P<0.01$ versus control; ANOVA with Tukey's multiple comparison test

specific marker for neuronal cells, once again, no LCN2 ${ }^{+} \beta I I-$ $\mathrm{TUB}^{+}$cells were observed $72 \mathrm{~h}$ after incubation with vehicle (Figure $3 c$ ), LPS (Figure $3 d$ ) or $A \beta_{1-42}$ (Figure 3e). However, we found cells that did not express $\beta$ III-TUB and stained positively for LCN2. These cells, which represented $<5 \%$ of the total cells in culture, were $\mathrm{GFAP}^{+}$astrocytes producing LCN2 $72 \mathrm{~h}$ after stimulation with LPS (Figure $3 \mathrm{~g}$ ) or $\mathrm{A} \beta_{1-42}$ (Figure 3h).

Lcn2(-I-) astrocytes present higher dehydrogenase activity and survival in response to $A \beta_{1-42}$. To investigate whether LCN2 produced in response to $1 \mu \mathrm{M} \mathrm{A} \beta_{1-42}$ was protective or detrimental, we further investigated the cellular dehydrogenase activity and survival of CP epithelial cells, astrocytes and neurons, isolated from the brains of Lcn2 $(+/+)$ and of $L c n 2\left(-I_{-}\right)$mice, upon in vitro stimulation. The cellular dehydrogenase activity was measured by the ratio between the absorbance value relative to tetrazolium reduction and the total number of cells. The response to $100 \mathrm{ng} / \mathrm{ml}$ LPS, which induces the secretion of LCN2 and influences the cellular dehydrogenase activity and the survival of astrocytes, but not of neurons, ${ }^{20}$ was used as positive control. No differences on the basal activity of dehydrogenases were observed between brain cells isolated from $L c n 2(+/+)$ and those isolated from $\operatorname{Lcn} 2(-/-)$ mice (Supplementary Figures $2 \mathrm{~A}-\mathrm{C}$ ). Regardless of the cell's genotype, neither $\mathrm{A} \beta_{1-42}$ nor LPS influenced the activity of dehydrogenases of $\mathrm{CP}$ epithelial cells when compared with the respective genotype control (Supplementary Figure 3). On the contrary, $L c n 2(+/+)$ astrocytes presented a significant decreased dehydrogenase activity, $48 \mathrm{~h}$ after treatment with $\mathrm{A} \beta_{1-42}$ or with LPS, when compared with the respective genotype control; an effect that was more pronounced at $72 \mathrm{~h}$ (Figure 4a). Interestingly, at 48 and 

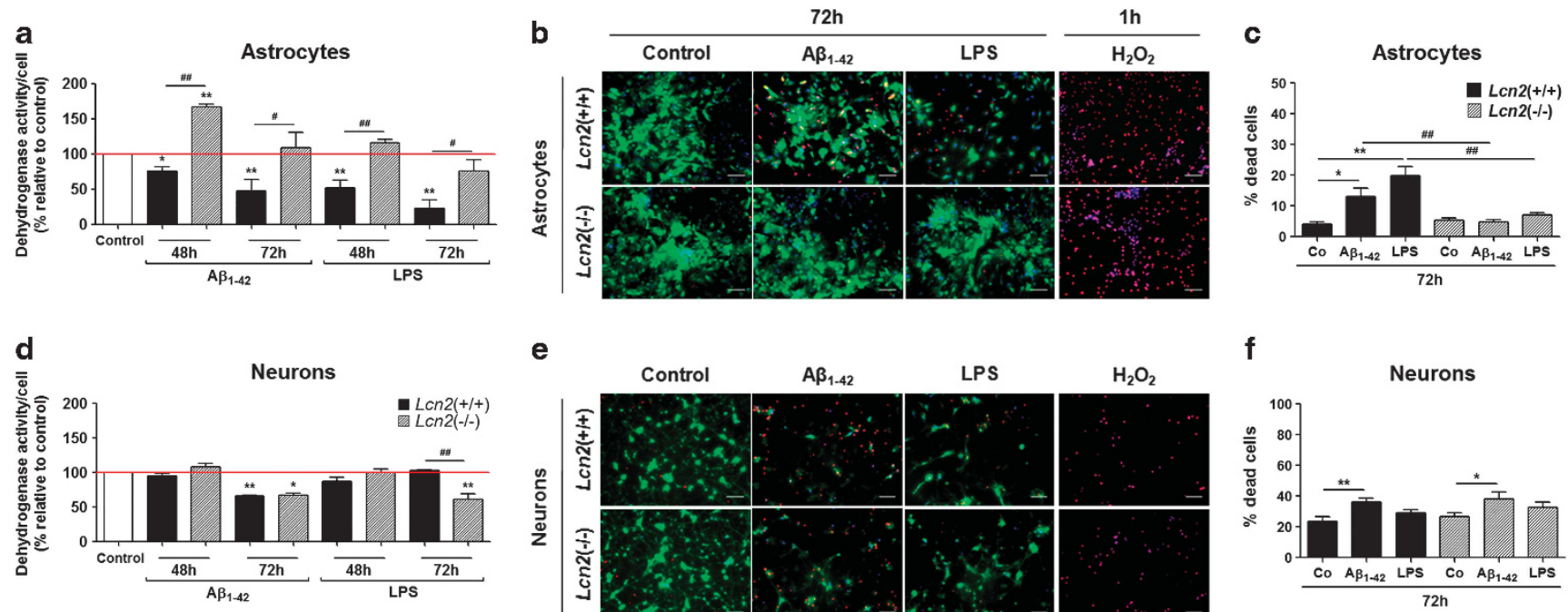

e

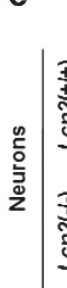

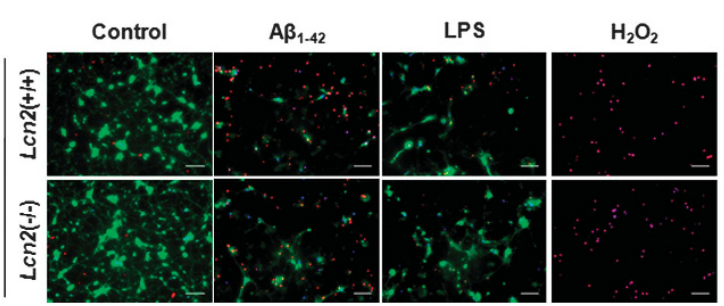

f

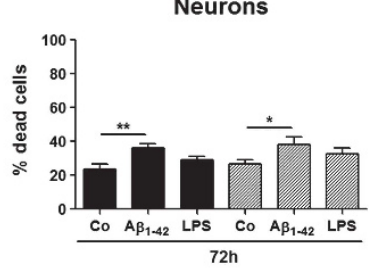

Figure $4 \mathrm{~A} \beta_{1-42}$ differentially affects the activity of cellular dehydrogenases and survival of $L \mathrm{Ln} 2(+/+)$ and of $L \mathrm{cn} 2(-/-)$ astrocytes and neurons. (a) $1 \mu \mathrm{M} \mathrm{A} \beta_{1-42}$ and $100 \mathrm{ng} / \mathrm{ml}$ LPS induced a decrease in the dehydrogenase activity of $\operatorname{Lcn} 2(+/+$ ) astrocytes (black bars) when compared with vehicle-treated cells from the same genotype (control, red line). Lcn2( - I - ) astrocytes (dashed bars) presented a higher dehydrogenase activity, 48 or $72 \mathrm{~h}$ after treatment with A $\beta_{1-42}$ and LPS, when compared with $L c n 2(+I+)$ astrocytes. (b) The number of live (green) and dead (red) $L c n 2(+I+)$ or $L c n 2(-I-)$ astrocytes was assessed $72 \mathrm{~h}$ after treatment with vehicle (control), $A \beta_{1}$. ${ }_{42}$ or LPS. Treatment of astrocytes with $30 \% \mathrm{H}_{2} \mathrm{O}_{2}$ was used as positive control for cell death. (c) $L \mathrm{cn} 2(+/+)$ astrocytes are more susceptible to the toxic effects of $A \beta_{1-42}$ and LPS, as shown by the increased percentage of dead cells in comparison with $L c n 2(-/-)$ astrocytes. (d) The dehydrogenase activity of $L c n 2(+I+)$ and $L c n 2(-/-)$ neurons decreased equally at $72 \mathrm{~h}$ after treatment with $\mathrm{A} \beta_{1-42}$, whereas LPS affected the dehydrogenase activity of $L c n 2(-/-)$ neurons only. (e) The number of live (green) and dead (red) $L c n 2\left(+I+\right.$ ) or $L c n 2\left(-I-\right.$ ) neurons was assessed $72 \mathrm{~h}$ after treatment with vehicle (control), $\mathrm{A} \beta_{1-42}$ or LPS. Treatment of neurons with $30 \% \mathrm{H}_{2} \mathrm{O}_{2}$ was used as positive control for cell death. (f) Despite the higher percentage of dead neurons after treatment with $A \beta_{1-42}$, no differences were observed between the percentages of dead $L c n 2(+I+)$ neurons and of dead $L c n 2(-I-)$ neurons, after stimulation with $A \beta_{1-42}$ or LPS. Results are presented as mean \pm S.E.M. ( $N \geq 4 /$ group) of percentage increase of the corresponding genotypes and are representative of two (b-f) or four (a) independent experiments. Scale bars $=50 \mu \mathrm{m} .{ }^{*} P<0.05$ and ${ }^{* *} P<0.01$ versus control; ${ }^{\#} P<0.05$ and ${ }^{\# \#} P<0.01$ versus LCn2( $-I-$ ); ANOVA with Tukey's multiple comparison test

$72 \mathrm{~h}$, the percentage of dehydrogenase activity of $\operatorname{Lcn} 2(-1-)$ astrocytes was significantly higher than that of $L c n 2(+/+)$ cells submitted to the same treatments; noticeably, the dehydrogenase activity of $L c n 2(-/-)$ astrocytes increased $48 \mathrm{~h}$ after incubation with $\mathrm{A} \beta_{1-42}$ or LPS and reached control levels after $72 \mathrm{~h}$ (Figure 4a). We next questioned whether the previous differences in cellular dehydrogenase activity were correlated with increased cell death (Figures $4 \mathrm{~b}$ and $\mathrm{c}$ ). Both treatments, with $1 \mu \mathrm{M} \mathrm{A} \beta_{1-42}$ or $100 \mathrm{ng} / \mathrm{ml}$ LPS, increased the percentage of dead $\operatorname{Lcn} 2(+/+)$ astrocytes at $72 \mathrm{~h}$, when compared with vehicle-treated $\operatorname{Lcn} 2(+/+)$ astrocytes (Figure 4c). Moreover, after incubation with $A \beta_{1-42}$ or LPS for $72 \mathrm{~h}$, the percentage of dead $L c n 2(+/+)$ astrocytes was significantly higher when compared with that of $\operatorname{Lcn} 2(-/-)$ astrocytes (Figure 4c). Treatments did not affect Lcn2(-I - ) astrocytes (Figure 4c).

Neurons from both genotypes, $\operatorname{Lcn} 2(+/+)$ and $\operatorname{Lcn} 2(-/-)$, were equally affected by $1 \mu \mathrm{M} \mathrm{A} \beta_{1-42}$, which decreased neuronal dehydrogenase activity (Figure $4 \mathrm{~d}$ ) and increased the percentage of dead cells $72 \mathrm{~h}$ after incubation (Figures $4 \mathrm{e}$ and f). Unexpectedly, incubation with $100 \mathrm{ng} / \mathrm{ml}$ LPS, described not to influence neuronal dehydrogenase activity, ${ }^{20}$ induced a decrease in the activity of dehydrogenases of $L c n 2(-I-)$ neurons, but did not affect $L c n 2(+I+)$ neurons (Figure 4d); yet this effect did not translate into an increased percentage of dead Lcn2(-I-) neurons (Figure 4f).

LCN2 modulates the expression of Bim, iron- and inflammation-related genes in astrocytes. We next explored possible mechanisms linking higher production and secretion of LCN2 to increased $\mathrm{A} \beta_{1-42}$ toxicity. As LCN2 is known to induce apoptosis through the overexpression of the proapoptotic gene $\mathrm{Bim},{ }^{14}$ we next analyzed the expression of Bim in rat astrocytes treated with $1 \mu \mathrm{M} \mathrm{A} \beta_{1-42}$. Bim expression was upregulated $24 \mathrm{~h}$ after incubation with $\mathrm{A} \beta_{1-42}$ and returned to basal levels at $72 \mathrm{~h}$ (Figure $5 \mathrm{a}$ ). As mentioned before, CP epithelial cells also presented Bim overexpression after $48 \mathrm{~h}$ of incubation with $\mathrm{A} \beta_{1-42}$ (Figure 1e), nevertheless this increased expression did not translate into changes in cellular dehydrogenase activity (Supplementary Figure 3). Given that BIM exerts its proapoptotic effect by interacting with anti-apoptotic proteins located in the mitochondria, ${ }^{21}$ we next quantified the percentage of astrocytes that presented co-localization of the mitochondrial marker MitoTracker (MitoT) and BIM. We observed a time-dependent progressive increase in the percentage of cells that presented BIM and MitoT co-localization (Figures $5 b$ and c). To further investigate the mechanism responsible for the increased susceptibility of $\operatorname{Lcn} 2(+/+)$ astrocytes to $\mathrm{A} \beta_{1-42}$, we next measured the expression of iron-related and proinflammatory genes. As seen in rat astrocytes (Figure 2a), mice $\operatorname{Lcn} 2(+/+$ ) astrocytes similarly presented a significant increase in Lcn2 expression 24 and $48 \mathrm{~h}$ after incubation with $1 \mu \mathrm{M} \mathrm{A} \beta_{1-42}$ (Figure $5 \mathrm{~d}$ ). Treatment equally induced the expression of $24 p 3 r$ in $L c n 2(+/+)$ and $L c n 2(-/-)$ astrocytes (Figure 5e), but had no effect on the expression of Hmox2 (Figure 5i). Of notice, $A \beta_{1-42}$ induced the expression of Lrp2, Bim, Hmox1, Fth, $1 / 6$ and chemokine (C-X-C motif) ligand 10 (Cxc/10) only in $\operatorname{Lcn} 2(+/+)$ astrocytes (Figures $5 f-h$ and $j-I)$. 

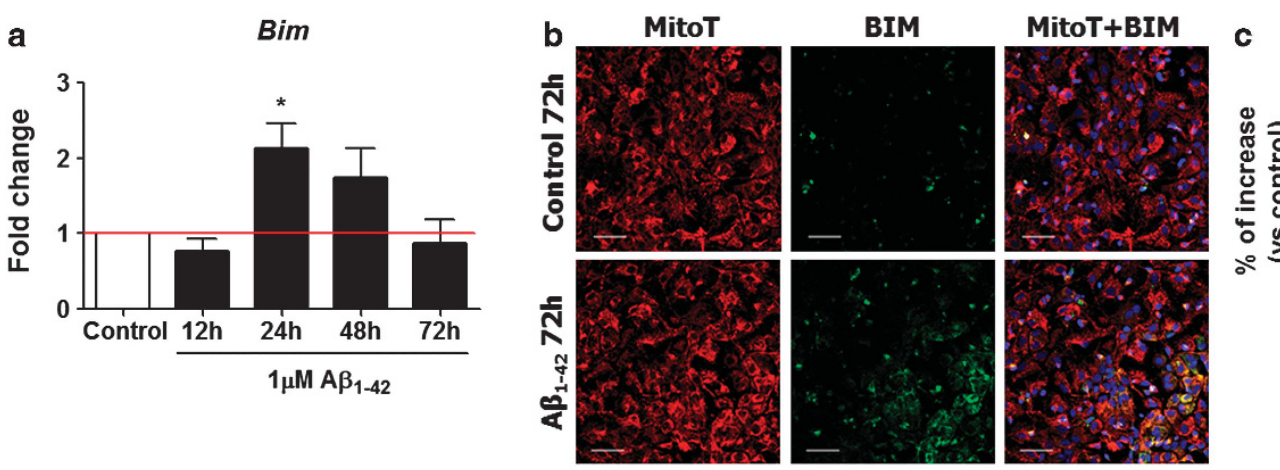

BIM $^{+}$Mito $^{+} /$total cells

d

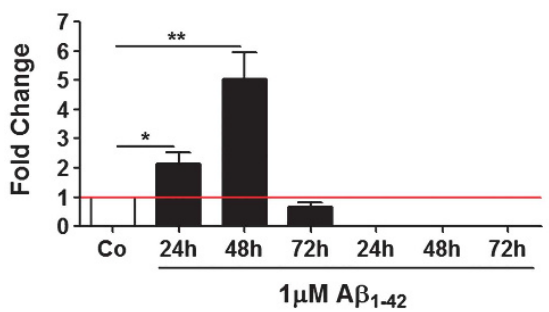

g

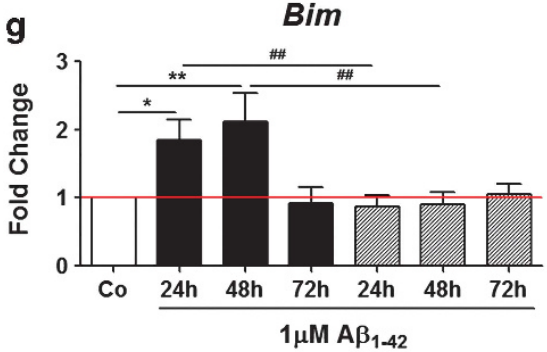

j

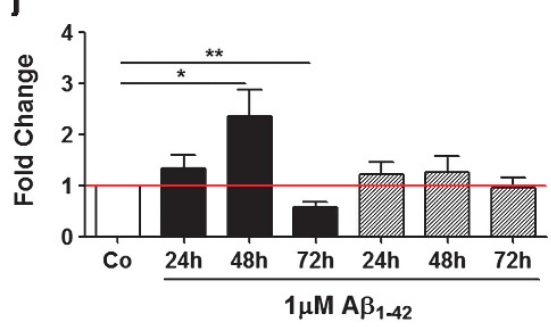

e

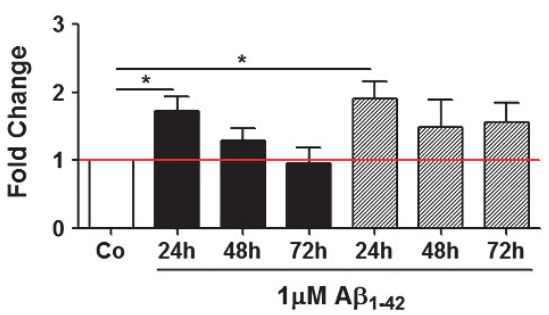

h

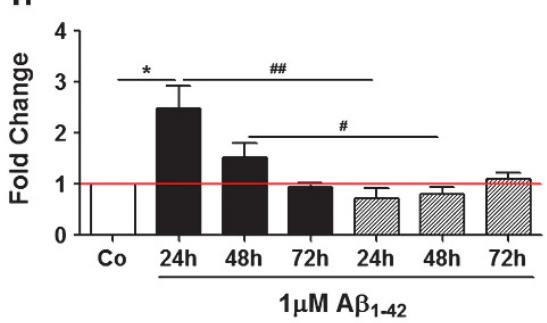

I/6

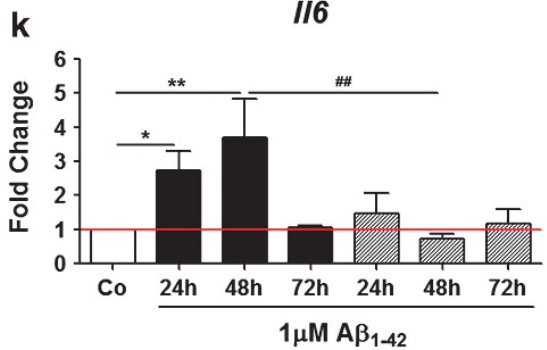

f

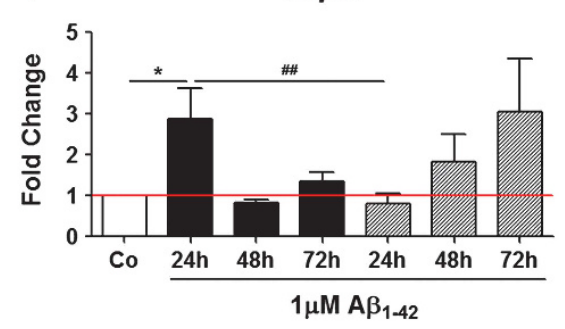

Hmox2

i

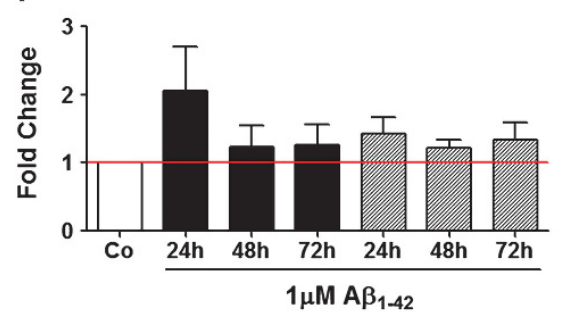

Cxc/10

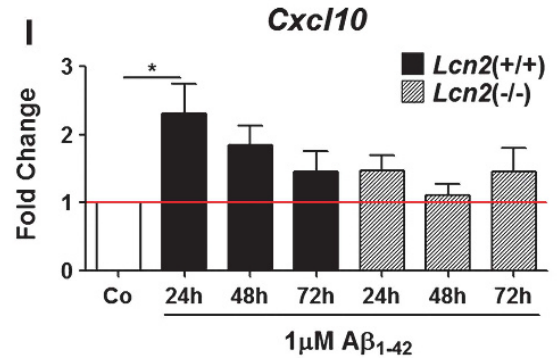

Figure 5 Expression of Bim, inflammatory and iron-related genes in $L c n 2(+/+)$ and $L c n 2\left(-/\right.$ - ) astrocytes is differentially modulated by $A \beta_{1-42 .}$. (a) mRNA level of Bim was increased in rat astrocytes $24 \mathrm{~h}$ after incubation with $A \beta_{1-42}$. (b) Astrocytes were stained with a mitochondrial marker, MitoT (red), with a specific antibody for BIM (green) and with DAPI (blue). Increased BIM staining was observed after incubation with $A \beta_{1-42}$. (c) $A \beta_{1-42}$ induced a significant and progressive increase in the percentage of astrocytes that presented MitoT and BIM co-localization 24, 48 and $72 \mathrm{~h}$ after incubation. (d-I) Lcn2 expression (d) was significantly upregulated in mouse Lcn2( + I+) astrocytes (black bars), 24 and $48 \mathrm{~h}$ after incubation with $A \beta_{1-42}$, when compared with the respective time-point control (red line). No Lcn2 expression was detected in Lcn2( - I - ) astrocytes (dashed bars). Except for 24p3r (e) and Hmox2 (i), A $\beta_{1-42}$ induced an increase in the mRNA levels of $\operatorname{Lrp2}(\mathbf{f}) \operatorname{Bim}(\mathbf{g}), \operatorname{Hmox1}(\mathbf{h}), \operatorname{Fth}(\mathbf{j}), 1 / 6(\mathbf{k})$ and Cxcl10 (I) in $L C n 2(+I+)$ astrocytes, but not in $L C n 2(-I-)$ astrocytes. Results are presented as mean \pm S.E.M. ( $N \geq 5 / g r o u p)$ and are representative of two (b and $\mathbf{c}$ ) or three $(\mathbf{a}, \mathbf{d}-\mathrm{I})$ independent experiments. Scale bars $=25 \mu \mathrm{m} .{ }^{*} P<0.05$ and ${ }^{* *} P<0.01$ versus control; ${ }^{\#} P<0.05$ and ${ }^{\# \#} P<0.01$ versus $L$ cn2( $\left.-I-\right)$; ANOVA with Tukey's multiple comparison test

Exogenous LCN2 leads to death of astrocytes. Astrocytes isolated from $\operatorname{Lcn} 2(-/-)$ mice were shown to be resilient to $\mathrm{A} \beta_{1-42}$ toxicity. To assess if this protection could be reverted, exogenous LCN2 alone or combined with $\mathrm{A} \beta_{1-42}$ was added to the culture medium supernatant of astrocytes. Lcn2 $(+/+)$ or $L c n 2(-/-)$ astrocytes were treated for $72 \mathrm{~h}$ with vehicle, $1 \mu \mathrm{M} \mathrm{A} \beta_{1-42}$ alone, $100 \mathrm{ng} / \mathrm{ml}$ LCN2 alone or
$1 \mu \mathrm{M} \mathrm{A} \beta_{1-42}$ plus $100 \mathrm{ng} / \mathrm{ml}$ LCN2 (Figures $6 \mathrm{a}$ and $\mathrm{b}$ ). Once again, incubation with $100 \mathrm{ng} / \mathrm{ml}$ LPS was used as a positive control for LCN2 production by $L c n 2(+/+)$ astrocytes. All treatments resulted in increased percentage of dead Lcn2 $(+/+)$ astrocytes (Figures $6 a$ and b). Notably, LCN2, alone or combined with $\mathrm{A} \beta_{1-42}$, was able to significantly increase the percentage of dead Lcn2(-/-) astrocytes, 


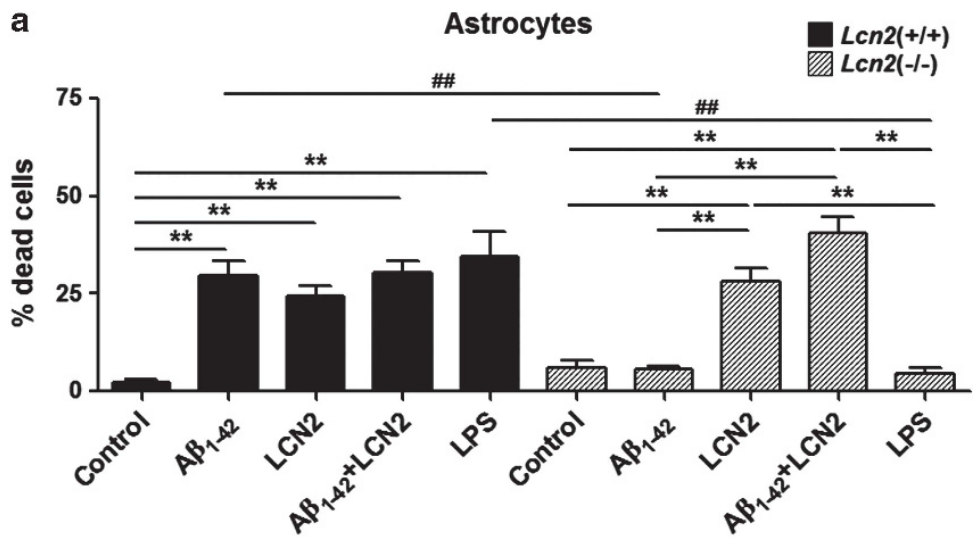

b

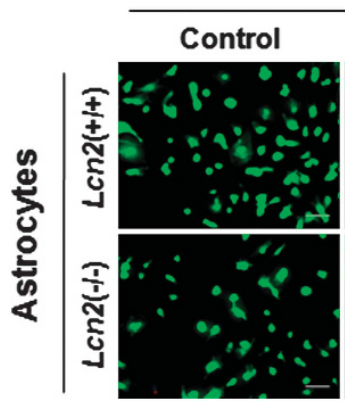

$72 \mathrm{~h}$

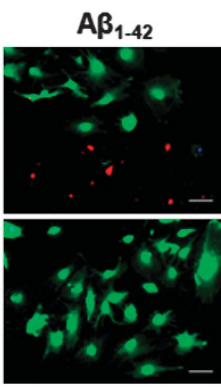

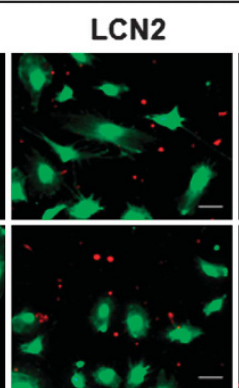
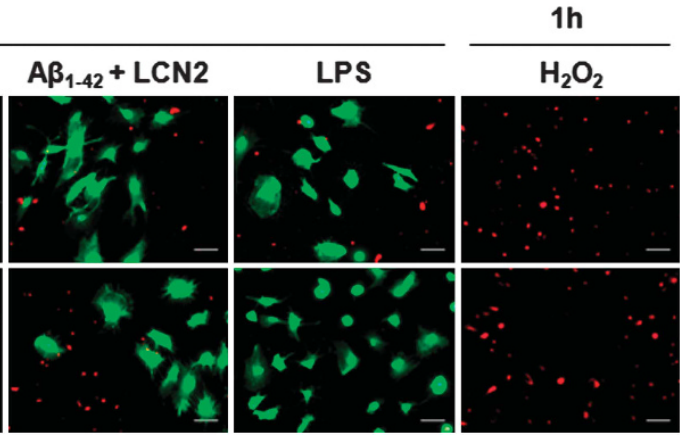

Figure 6 Exogenous $L C N 2$ alone or together with $A \beta_{1-42}$ induces an increase in the percentage of dead astrocytes. (a) The percentage of dead $L c n 2(+/+)$ astrocytes (black bars) increased significantly after $72 \mathrm{~h}$ of incubation with $1 \mu \mathrm{M} \mathrm{A} \beta_{1-42}, 100 \mathrm{ng} / \mathrm{ml} \mathrm{LCN} 2, \mathrm{~A} \beta_{1-42}$ plus LCN2 or with $100 \mathrm{ng} / \mathrm{ml} \mathrm{LPS}$. In response to the same treatments, the percentage of dead LCn2(-I-) astrocytes (dashed bars) was only increased in response to LCN2 or A $\beta_{1-42}$ plus LCN2. (b) Representative images of live (green) and dead (red) $L c n 2\left(+/+\right.$ ) or $L c n 2(-/-)$ astrocytes after treatment with $A \beta_{1-42}$, LCN2, $A \beta_{1-42}$ plus LCN2 or LPS for $72 \mathrm{~h}$. Treatment of astrocytes with $30 \% \mathrm{H}_{2} \mathrm{O}_{2}$ for $1 \mathrm{~h}$ was used as positive control for cell death. Results are presented as mean \pm S.E.M. ( $N \geq 4$ /group) of percentage increase. Scale bars $=25 \mu \mathrm{m}$. ${ }^{* *} P<0.01$ versus control; $\# \#<0.01$ versus Lcn2 $(-/-)$; ANOVA with Tukey's multiple comparison test

when compared with control cells, whereas $A \beta_{1-42}$ alone or LPS alone were not (Figure 6a).

\section{Discussion}

Herein, we provide evidence for a novel role of LCN2 as a mediator of $\mathrm{A} \beta$ cytotoxicity. Specifically, we show that incubation with $A \beta_{1-42}$ induces the expression of $L c n 2$, and its secretion, by CP epithelial cells and by astrocytes, but not by microglia or neurons, isolated from the brain of both rats and mice. Moreover, we show that $\mathrm{A} \beta_{1-42}$ significantly reduces the dehydrogenase activity and survival of astrocytes that produce LCN2, an effect that is abrogated in astrocytes from Lcn2( - I - ) mice. The protection of $L c n 2(-I-)$ astrocytes to $\mathrm{A} \beta_{1-42}$-mediated toxicity is lost by the addition of exogenous LCN2.

We addressed the role of LCN2 in $A \beta$ toxicity by studying the response of four cell types: CP epithelial cells, astrocytes, microglia and neurons. CP epithelial cells constitute, in vivo, the blood-cerebrospinal fluid (CSF) barrier and produce most of the constituents of the CSF. Importantly, CP epithelial cells are also involved in the excretion of $A \beta$ out of the brain through different pathways. ${ }^{22,23}$ One of these pathways is mediated by LRP2, which is expressed by CP epithelial cells and was shown to lead to $A \beta$ internalization and removal from the CSF in a mouse model of $A D .{ }^{24}$ Here we show that, despite the increased production of LCN2 protein after stimulation with
$\mathrm{A} \beta_{1-42}, \mathrm{CP}$ epithelial cells seem to deal with the toxicity caused by these peptides, through mechanisms that deserve further investigation.

Astrocytes, the most abundant cells in the brain, interact with neurons and regulate neuronal homeostasis, ${ }^{25}$ through the secretion of several molecules, including LCN2. ${ }^{26}$ Production of LCN2 by astrocytes was previously described both in vitro, in response to proinflammatory cytokines such as interferon- $\gamma$ and TNF, ${ }^{17,26}$ and in vivo, in models of CNS neuroinflammatory diseases like experimental autoimmune encephalomyelitis ${ }^{19}$ and spinal cord injury. ${ }^{27}$ Interestingly, also microglial cells were shown to respond to LCN2, which seems to favor their polarization into a M1-activated phenotype ${ }^{28}$ Here, we show that LCN2 is not produced by microglia in response to $\mathrm{A} \beta_{1-42}$, both in astrocyte-enriched cultures $(<5 \%$ microglia) and in microglia-enriched cultures.

Given that neurodegeneration is a critical feature of $A D$ and that neurons are highly sensitive to monomeric/dimeric $A \beta_{1-42}$ toxicity, ${ }^{1,29}$ we also studied neurons. We clearly show that, in vitro, Lcn2 expression is not altered in neurons and that LCN2 protein is not produced by these cells, neither in basal conditions nor in response to LPS or $\mathrm{A} \beta_{1-42}$. Others have suggested that, in vitro, LCN2 is produced by neurons in response to $\mathrm{TNF}^{8}$ or to the less toxic $A \beta_{1-40}$ peptide $^{30}$ and, in vivo, by neurons from the hippocampus of mice submitted to acute stress. ${ }^{31}$ This discrepancy may be related to the different stimuli studied or to neuron-enriched culture 
contamination by astrocytes that can easily proliferate in culture, even after treatment with inhibitors of cellular proliferation. In accordance, we observed that a small percentage of astrocytes $(<5 \%)$ present in the neuronalenriched cultures treated with $\mathrm{A} \beta_{1-42}$ or LPS, stained positively for LCN2. Of relevance and concomitant to our observations, a recent study states that, in the brain, only reactive astrocytes are able to produce LCN2 and that, when secreted, this protein is a potent mediator of neurotoxicity. ${ }^{26}$

Importantly, in response to $\mathrm{A} \beta_{1-42}, \mathrm{LCN} 2$ appears to mediate the overexpression of proinflammatory and ironrelated genes in astrocytes, favoring the already described neurotoxic phenotype. ${ }^{32}$ One of these genes encodes for the proinflammatory cytokine interleukin-6 (IL-6), which is highly expressed by $\operatorname{Lcn} 2(+/+)$ astrocytes in response to $\mathrm{A} \beta_{1-42}$, supporting previous observations upon treatment with $\mathrm{A} \beta_{1-40 .}{ }^{33}$ The implication of LCN2 in this process stems from the observation that $\mathrm{A} \beta_{1-42}$ is not able to upregulate $/ / 6$ expression in $L c n 2(-/-)$ astrocytes. This regulatory loop between LCN2 and IL- 6 seems to happen in both directions, as others have observed that $I I 6(-I-)$ mice injected with LPS present a lower expression of Lcn2 in the hypothalamus when compared with $1 / 6(+/+)$ mice. ${ }^{34}$ Similarly, the expression of $I 16$ and $C x c / 10$ was upregulated in $L c n 2(+/+)$ astrocytes, but not in $L c n 2(-/-)$ astrocytes, in response to $A \beta_{1-42}$. Previous studies have shown that different cell populations from the CNS are able to upregulate the expression of $\mathrm{CxCl10}$ after treatment with LCN2, which, in turn, promotes the activation and migration of glial cells within the CNS. ${ }^{16,28}$ Moreover, $\mathrm{A} \beta_{1-42}$ led to an overexpression of Hmox1 and Fth in $\mathrm{CP}$ epithelial cells and in astrocytes. It is well established that both CP epithelial cells and astrocytes have an important role in brain iron metabolism and changes in the expression of ironrelated genes are often correlated with alterations in the level of intracellular/extracellular iron ratio under stressful conditions. ${ }^{35,36}$ Of relevance, we show that the changes observed in the expression of $H$ mox 1 and $F$ th in response to $A \beta_{1-42}$ are abrogated in $L c n 2(-/-)$ astrocytes, suggesting that signaling through LCN2 may directly or indirectly regulate the expression of genes involved in iron metabolism. Ultimately, high levels of extracellular LCN2, secreted by CP epithelial cells or astrocytes in response to $\mathrm{A} \beta_{1-42}$, can also impact on the level of extracellular iron, thus promoting the formation and stabilization of toxic $A \beta$ intermediates ${ }^{2}$ and increase the level of oxidative and mitochondrial damage in brain cells. ${ }^{37,38}$

Also of relevance, LCN2 produced in response to $\mathrm{A} \beta_{1-42}$ led to dehydrogenase dysfunction and increased apoptosis. Others have shown that LCN2 is an autocrine mediator of astrocytosis, able to decrease the viability of astrocytes and to increase the levels of oxidative damage by boosting the effects of other noxious agents, such as sodium nitroprusside dihydrate or LPS. ${ }^{17}$ Mechanistically, it was shown that $24 \mathrm{p} 3 \mathrm{R}$ is able to internalize apo-LCN2, promoting the removal of iron from cells, which increases the level of BIM and cell apoptosis. $^{14}$ This is in agreement with another study, reporting that apo-LCN2 secreted by astrocytes promotes neuronal death in a concentration-dependent manner; ${ }^{26}$ an effect that seems to be ablated if neurons are incubated with apo-LCN2 plus iron-siderophore complexes. ${ }^{15}$ Supporting these findings, we now show that monomeric/dimeric $\mathrm{A} \beta_{1-42}$ increases the expression of $24 p 3 r$ in astrocytes and neurons. Therefore, LCN2, secreted in response to $\mathrm{A} \beta_{1-42}$ and internalized through $24 \mathrm{p} 3 \mathrm{R}$, can be an autocrine or paracrine modulator of brain cell viability, via the iron-responsive proapoptotic protein BIM (Figure 7). Overexpression of Lcn2, 24p3r and Lrp2 in Lcn2 $(+/+)$ astrocytes is accompanied by a progressive and significant decrease in the activity of cellular dehydrogenases and increased cell death; which is not observed in $L c n 2(-/-)$ astrocytes. This can be due to a progressive increase of BIM that translocates into the mitochondria in a process known to culminate in cell apoptosis. ${ }^{21,39}$ Notably, the overexpression of Bim is also regulated by LCN2, given that Bim expression is not induced in $\operatorname{Lcn} 2(-/-)$ astrocytes upon stimulation with $\mathrm{A} \beta_{1-42}$. Concomitantly, after incubation with $\mathrm{A} \beta_{1-42}$ or LPS, the percentage of dead $L c n 2(-/-)$ astrocytes was lower than that of $L c n 2(+/+)$ astrocytes, which reinforces the view that in the absence of LCN2 the toxic effects of both $\mathrm{A} \beta_{1-42}$ and LPS are reduced. However, taking into account recent observations suggesting that LCN2 alone is not able to induce apoptosis in astrocytes, ${ }^{26}$ we cannot discard an indirect modulation of astrocytes' survival by molecules secreted by activated microglia ( $<5 \%$ in astrocyte-enriched cultures), because of their ability to respond to LCN2. ${ }^{28}$ In fact, others have shown that in response to LPS, microglia are able to influence the survival of brain cells, oligodendrocytes in particular, by secreting proinflammatory molecules like $\mathrm{TNF},{ }^{40}$ and that this process is modulated, in vivo, by LCN2. ${ }^{28}$

Of notice, neuronal apoptosis in response to $A \beta_{1-42}$ is independent of their ability to produce LCN2 as the survival of Lcn2 $(+/+)$ and Lcn2( - I - ) neurons significantly decreased in response to $\mathrm{A} \beta_{1-42}$. Nevertheless, we show that $24 p 3 r$ is overexpressed by neurons after incubation with monomeric/ dimeric $\mathrm{A} \beta_{1-42}$, which means that despite their inability to produce LCN2, these cells may be able to respond to it. Whether LCN2 is involved in neuronal overexpression of $\mathrm{Bim}$, which was shown to mediate apoptosis in response to $\mathrm{A} \beta_{1-42},{ }^{41}$ needs to be further investigated.

Our observations clearly support a role for LCN2 as a modulator of the response of astrocytes to $\mathrm{A} \beta$ peptides. Interestingly, LCN2 is an acute-phase protein able to modulate the expression of key proinflammatory mediators in glial cells, such as IL-12, IL-23, TNF and inducible nitric oxide synthase, ${ }^{16}$ that can ultimately influence glial and neuronal morphology, migration and also sensitize these brain cells to oxidative damage and apoptosis. ${ }^{15,17}$ Of relevance, the expression of most of these proinflammatory molecules, including LCN2, can be upregulated through Toll-like receptor $4,{ }^{42}$ which is activated by LPS, but is also closely involved in the binding of extracellular $\mathrm{A} \beta$ peptides. ${ }^{43}$ Toll-like receptor 4 signaling cascades, which are distinct between glial cells and neurons, ${ }^{44}$ might also explain the differences that we observe concerning the production of LCN2, a topic that warrants further investigation. Accordingly, it was recently shown that astrocytes isolated from the brain of $L c n 2(-/-)$ mice are unable to express the classical proinflammatory genes in response to LPS and interferon- $\gamma .{ }^{32}$ We observed the same kind of gene expression abrogation in Lcn2 ( - / - ) astrocytes after treatment with $\mathrm{A} \beta_{1-42}$, which may denote an anti-inflammatory phenotype that is conferring 


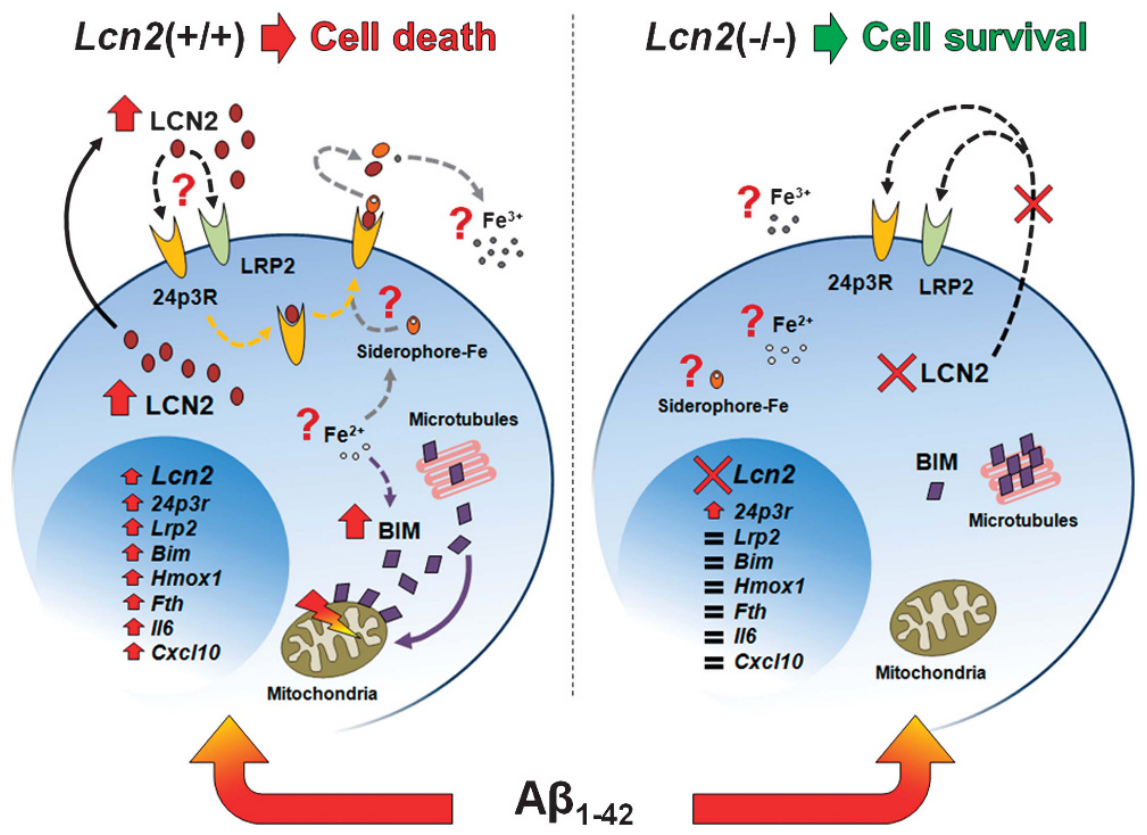

Figure 7 LCN2 is induced by $A \beta_{1-42}$ and modulates cell survival. LCn2 is one of the genes highly expressed by CP epithelial cells and astrocytes in response to $A \beta_{1-42}$. This increase is similarly reflected at the LCN2 protein level. $A \beta_{1-42}$ induces the expression of $24 p 3$ rand $L r p 2$, genes that encode for receptors that bind LCN2 and can lead to its internalization. LCN2 internalization may mediate the increase in proapoptotic BIM and its translocation into the mitochondria. Ultimately, $L \mathrm{cn} 2(+/+)$ astrocytes, which produce and secrete LCN2 in response to $A \beta_{1-42}$, present a decreased viability when compared with $\operatorname{LCn} 2(-/-)$ astrocytes. Of notice, the production of LCN2 is somehow mediating the expression of genes involved in iron metabolism and in the proinflammatory response to $A \beta_{1-42}$. It is still unclear if this LCN2-mediated apoptotic mechanism occurs through alterations in the level of intracellular/extracellular iron ratio. However, these observations strongly suggest that LCN2 participates in the early proinflammatory response induced by $\mathrm{A} \beta$ peptides

protection in response to these toxic peptides (Figure 7). Curiously, others have shown that $\mathrm{A} \beta$ peptides promote calcium-dependent activation of NADPH oxidase in astrocytes, but not in neurons, which is closely associated with increased neurodegeneration. ${ }^{45}$ Given this observation, it will be important to further elucidate on the involvement of $A \beta$ induced calcium signaling and mitochondrial dysfunction as triggers for increased LCN2 production and secretion by astrocytes. Importantly, it has been previously shown that LCN2 is able to modulate neuronal function, particularly neuronal excitability, through the modulation of neuronal spine formation and morphology. ${ }^{31}$ Thus, produced in response to $\mathrm{A} \beta_{1-42}$, LCN2 can regulate important mechanisms and pathways that are critical for brain cell activation ${ }^{31,32}$ and that may ultimately lead to alterations in brain areas involved in cognition and memory, which are affected in AD. ${ }^{46}$ In agreement, patients with mild cognitive impairment present high levels of LCN2 in the plasma ${ }^{47}$ and low levels of LCN2 in the CSF, ${ }^{8}$ which points to an imbalance of LCN2 levels in the brain in the early phases of dementia. It is clear, thus, that the role of LCN2 in neurodegenerative disorders such as AD warrants further investigation. This study adds an important piece into the field by showing that LCN2 is required for A $\beta$ toxicity to astrocytes, which becomes a natural target to modulate in AD.

\section{Materials and Methods}

Animal strains and genotyping. Animal handling and experiments were conducted in accordance with the Portuguese National Authority for Animal Experimentation, Direção Geral de Veterinária (ID:DGV9457). Animals were kept in accordance with the guidelines for the care and handling of laboratory animals in the Directive 2010/63/EU of the European Parliament and Council. For cell culture experiments, Wistar Han rat post-natal day 0 (P0)-P1 pups were used to perform primary cultures of neurons and P5-P7 pups to perform cultures of astrocytes, microglia or CP epithelial cells. In addition, $\operatorname{Lcn} 2(-/-)$ mice ${ }^{48}$ and the respective wild-type littermate controls, $\operatorname{Lcn} 2(+/+)$, raised in a C57BL/6J background were used.

Primary cultures of CP epithelial cells. CP epithelial cells from rats or mice pups were used to determine the response to $A \beta$. CP epithelial cells were prepared as described elsewhere, ${ }^{49}$ with minor modifications. Briefly, neonates (P5-P7) were killed and the CP dissected from the four brain ventricles, under a conventional light microscope (SZX7, Olympus, Hamburg, Germany). The tissue was rinsed twice in phosphate-buffered saline (PBS, Invitrogen, Carlsbad, CA, USA) without $\mathrm{Ca}^{2+}$ and $\mathrm{Mg}^{2+}$, followed by a 25 -min digestion with $0.1 \mathrm{mg} / \mathrm{ml}$ pronase (Sigma-Aldrich, St. Louis, MO, USA) at $37^{\circ} \mathrm{C}$. Predigested tissue was recovered by sedimentation and briefly shaken in $0.025 \%$ trypsin-EDTA (Invitrogen) containing $12.5 \mu \mathrm{g} / \mathrm{ml}$ DNAse I (Roche, Amadora, Portugal). The supernatant was then withdrawn and kept on ice with $10 \%$ fetal bovine serum (FBS, Invitrogen). This step was repeated five times. Cells were pelleted by centrifugation and re-suspended in culture media consisting of Ham's F-12 and Dulbecco's modified Eagle's medium (DMEM; $1: 1$; Invitrogen) supplemented with $10 \%$ FBS, $2 \mathrm{mM}$ glutamine, $50 \mathrm{mg} / \mathrm{ml}$ gentamycin, $5 \mathrm{mg} / \mathrm{ml}$ insulin, $5 \mathrm{mg} / \mathrm{ml}$ transferrin, $5 \mathrm{ng} / \mathrm{ml}$ sodium selenite, $10 \mathrm{ng} / \mathrm{ml}$ epidermal growth factor, $2 \mathrm{mg} / \mathrm{ml}$ hydrocortisone and $5 \mathrm{ng} / \mathrm{ml}$ basic fibroblast growth factor (all from Sigma-Aldrich). For further enrichment, cells were incubated on plastic dishes for $2 \mathrm{~h}$ at $37^{\circ} \mathrm{C}$. The supernatant containing the $\mathrm{CP}$ epithelial cells was collected and placed for seeding on $0.4 \mu \mathrm{m}$ pore size Transwells (Corning Life Sciences, Lowell, MA, USA) coated with laminin (BD Biosciences, Bedford, MA, USA) at a density of $1 \times 10^{5} \mathrm{cells} / \mathrm{cm}^{2}$. The culture medium was changed every 2 days and $\mathrm{CP}$ epithelial cells were maintained in culture for $5-7$ days, at $37^{\circ} \mathrm{C}$ in a humid atmosphere $\left(5 \% \mathrm{CO}_{2}\right)$, before performing the experiment. To assess the purity and confluence, cells were immunostained with a specific antibody for TTR (kindly provided by Dr. Maria Joao Saraiva, Institute for Molecular and Cell Biology, Porto, Portugal), a specific marker of CP epithelial cells. ${ }^{50}$ Cell counting revealed that $\geq 95 \%$ of the cells stained positive for TTR. 
Primary cultures of astrocytes. The experimental procedure to obtain primary cultures of astrocytes from the brain of P5-P7 rats or mice was the same as described elsewhere, with some modifications. ${ }^{51}$ Brain macro-dissection was performed in ice-cold PBS, without $\mathrm{Ca}^{2+}$ and $\mathrm{Mg}^{2+}$, under a conventional light microscope (SZX7, Olympus). Briefly, the olfactory bulbs were discarded and the contaminating $\mathrm{CP}$ and meninges were carefully removed. The whole forebrain and the cortices, including the hippocampus, were cut into smaller fragments and incubated for $30 \mathrm{~min}$ at $37^{\circ} \mathrm{C}$ in PBS supplemented with $0.025 \%$ trypsin-EDTA and $12.5 \mu \mathrm{g} / \mathrm{ml}$ DNAse I. The digested tissue fragments were washed three times with DMEM supplemented with $10 \%$ FBS, $0.5 \mathrm{mM}$ L-glutamine, $1 \%$ sodium pyruvate (Invitrogen) and 1\% penicillin-streptomycin (10000 units penicillin-10 mg streptomycin, Sigma-Aldrich) and mechanically dissociated through a 2-ml pipette and a Pasteur pipette. A single-cell suspension in supplemented DMEM was obtained and cells were plated on coverslips or culture wells (Nunc, Roskilde, Denmark) coated with poly-D-lysine (Sigma-Aldrich), at a density of $25000 \mathrm{cells} / \mathrm{cm}^{2}$. The culture medium was changed every 2 days and glial cells were maintained in culture for $5-7$ days, at $37^{\circ} \mathrm{C}$ in a humid atmosphere $\left(5 \% \mathrm{CO}_{2}\right)$. A confluent monolayer of astrocytes was formed and cells were $\geq 95 \%$ positive for GFAP.

Primary cultures of microglia. Microglia-enriched cultures were obtained as described elsewhere, with some modifications. ${ }^{51}$ Brain macro-dissection and cellular dissociation were performed following the same method described for astrocytes. Briefly, after obtaining a single-cell suspension, $1 \times 10^{6} \mathrm{cells} / \mathrm{cm}^{2}$ were plated in polystyrene T75 flasks (Thermo Scientific, Fremont, CA, USA), previously coated with poly-D-lysine (Sigma-Aldrich), and were maintained at $37^{\circ} \mathrm{C}$ in a humid atmosphere $\left(5 \% \mathrm{CO}_{2}\right)$ for 2 weeks, in supplemented DMEM, with periodical medium renewal. After that, the flasks were agitated in an orbital shaker at 240 r.p.m. during $4 \mathrm{~h}$. Following this, the medium containing detached microglia cells was collected, centrifuged at 1200 r.p.m. for $5 \mathrm{~min}$ and the cells were re-suspended in supplemented DMEM and plated at a density of $40000 \mathrm{cells} / \mathrm{cm}^{2}$ on coverslips coated with poly-D-lysine (Sigma-Aldrich). Microglial cells ( $\geq 95 \%$ positive for $\mathrm{CD} 11 \mathrm{~b}$ ) were then maintained at $37^{\circ} \mathrm{C}$ in a humid atmosphere $\left(5 \% \mathrm{CO}_{2}\right)$ until further testing.

Primary cultures of neurons. Primary cultures of neurons were obtained from the brains of newborn mice (P0-P1) as described elsewhere, with some modifications..$^{52}$ Briefly, the olfactory bulbs, meninges and $\mathrm{CP}$ were removed from the whole forebrain and the cortices, including the hippocampus, were dissected into smaller fragments, trypsinized for $30 \mathrm{~min}$ at $37^{\circ} \mathrm{C}$ and mechanically dissociated, following the same method described for glial cells. After that, the cells were washed five times with Hanks' balanced salt solution supplemented with $0.5 \%$ penicillin-streptomycin (Sigma-Aldrich), $10 \mathrm{mM}$ HEPES solution and $1 \%$ sodium pyruvate (Invitrogen) and re-suspended in minimum essential medium (Invitrogen) supplemented with 10\% FBS, 0.5\% glucose (Sigma-Aldrich), 0.5\% penicillin-streptomycin, $2 \mathrm{mM}$ L-glutamine and $1 \%$ minimum essential medium vitamins (Invitrogen). Cells were plated on coverslips or culture wells (Nunc) coated with poly-L-ornithine (Sigma-Aldrich), at a density of $50000 \mathrm{cells} / \mathrm{cm}^{2}$ and left at $37^{\circ} \mathrm{C}$ in a humid atmosphere $\left(5 \% \mathrm{CO}_{2}\right)$ for $5 \mathrm{~h}$. After this, the medium was changed into Neurobasal A (Invitrogen) supplemented with $0.5 \mathrm{mM}$ L-glutamine and 2\% B27 (Invitrogen). The culture medium was changed $24 \mathrm{~h}$ after for Neurobasal A with $2 \%$ B27, $1 \%$ newborn calf serum (Invitrogen), $0.5 \mathrm{mM}$ L-glutamine, $0.03 \mu \mathrm{M}$ uridine (Sigma-Aldrich), $0.07 \mu \mathrm{M}$ FDU (Sigma-Aldrich) and $1 \mu \mathrm{M}$ kynurenic acid (Sigma-Aldrich) to prevent the proliferation of cells undergoing mitotic division and to reduce enhanced synaptic transmission. The neuronal cells were maintained in culture for at least 15 days, in a humid atmosphere $\left(5 \% \mathrm{CO}_{2}\right)$ at $37^{\circ} \mathrm{C}$, before starting the experiment. After 15 days in culture, cells were $\geq 95 \%$ positive for the neuronal marker $\beta \| I-T U B$.

Cell treatment. Cells were treated with culture medium alone (vehicle or control), culture medium with $A \beta_{1-42}$ (American Peptide Company, Sunnyvale, $C A$, USA) or culture medium with bacterial LPS (Escherichia coli, serotype 055:B5, Sigma-Aldrich), after reaching confluence. $\mathrm{A} \beta_{1-42}$ was dissolved in Tris-NaCl buffer $(150 \mathrm{mM} \mathrm{NaCl}$ and $50 \mathrm{mM}$ Tris- $\mathrm{HCl} \mathrm{pH} 7.4$ from Sigma-Aldrich) to a final concentration of $221.5 \mu \mathrm{M}$ and kept in stock at $-80^{\circ} \mathrm{C}$. We chose to use preparations of soluble monomeric/dimeric $\mathrm{A} \beta_{1-42}$ as a cellular stimulator, as this is expected to mimic the form released by cells into the extracellular milieu. ${ }^{29,53}$ To stimulate the cells with 0.1 or $1 \mu \mathrm{M}$ monomeric/dimeric $\mathrm{A} \beta_{1-42}$, stock $\mathrm{A} \beta_{1-42}$ was dissolved in the appropriate culture medium. As shown in Supplementary Figure 1, during the incubation period these become oligomeric, which again mimics what seems to occur in vivo. ${ }^{1}$ Cells were also stimulated with $100 \mathrm{ng} / \mathrm{ml}$ LPS or $100 \mathrm{ng} / \mathrm{ml}$ LCN2 for 48 or $72 \mathrm{~h}$. Cells incubated with $30 \%$ $\mathrm{H}_{2} \mathrm{O}_{2}$ (Panreac Quimica, Cascais, Portugal) were used as positive controls for cell death.

Gene expression measurements by qRT-PCR. Total RNA was extracted from cells using the RNeasy Plus Micro Kit (Qiagen, Hamburg, Germany), following the manufacturer's instructions. RNA quality and quantification was assessed in the NanoDrop ND-1000 (NanoDrop, Thermo Scientific, Wilmington, DE, USA) and $500 \mathrm{ng}$ of RNA from each sample was reverse transcribed into cDNA using the iScriptTM cDNA Synthesis Kit (Bio-Rad Laboratories, Hercules, CA, USA) following the manufacturer's instructions. Primers used to measure the expression levels of selected mRNA transcripts of Rattus norvegicus and of Mus musculus by qRT-PCR were designed using the Primer3 software, ${ }^{54}$ on the basis of the respective GenBank sequences. The reference gene hypoxanthine guanine phosphoribosyl transferase (Hprt) was used as internal standard for the normalization of the selected transcripts' expression. All gene accession numbers and primer sequences are provided in Supplementary Table 1. Annealing temperatures are available on request. qRT-PCR was performed on a CFX 96TM real-time system instrument (Bio-Rad Laboratories), with the QuantiTect SYBR Green RT-PCR reagent kit (Qiagen) according to the manufacturer's instructions, using equal amounts of CDNA from each sample. The cycling parameters were 1 cycle at $95^{\circ} \mathrm{C}$ for $15 \mathrm{~min}$, followed by 40 cycles at $94^{\circ} \mathrm{C}$ for $15 \mathrm{~s}$, annealing temperature (primer specific) for $30 \mathrm{~s}$ and $72{ }^{\circ} \mathrm{C}$ for $30 \mathrm{~s}$, finishing with 1 cycle at $65^{\circ} \mathrm{C}$ to $95^{\circ} \mathrm{C}$ for $5 \mathrm{~s}$ (melting curve). Product fluorescence was detected at the end of the elongation cycle. All melting curves exhibited a single sharp peak at the expected temperature.

Immunocytochemistry and fluorescence microscopy. Cells were fixed in $4 \%$ paraformaldehyde at room temperature (RT) for $20 \mathrm{~min}$. If mitochondrial staining was required, before fixation, the cells were incubated with MitoTracker Red FM (MitoT, Invitrogen) for $30 \mathrm{~min}$ at $37^{\circ} \mathrm{C}$ in a humid atmosphere $\left(5 \% \mathrm{CO}_{2}\right)$, according to the manufacturer's instructions. Cells were then blocked with PBS $0.3 \%$ Triton X-100 (Sigma-Aldrich; PBS-T) with $0.5 \%$ bovine serum albumin (Sigma-Aldrich) for $1 \mathrm{~h}$ at RT. The different cell types were incubated for $1 \mathrm{~h}$ at RT with the primary antibodies for TTR (1:1000), GFAP (1:500, Dako, Golstrup, Denmark), CD11b (1:100, BioLegend, San Diego, CA, USA), $\beta$ III-TUB (1:500, Millipore Iberica, Madrid, Spain), LCN2 $(1: 400$, R\&D Systems, Minneapolis, MN, USA) or BIM $(1: 200$, Cell Signaling Technology, Beverly, MA, USA) diluted in PBS-T. Cells were washed and incubated with specific Alexa 488-conjugated or Alexa 594-conjugated secondary antibodies (Invitrogen) diluted in PBS-T $(1: 500)$ for $1 \mathrm{~h}$ at RT, according to the source and isotype of the primary antibodies. Cells were washed with PBS and incubated with 4',6-diamidino-2-phenylindole (DAPI, 1:1000, Invitrogen) in PBS for 5 min at RT. Finally, cells were washed with PBS, the glass coverslips were mounted in PermaFluor mounting medium (Thermo Scientific). Fluorescence analysis and image capture were performed using a conventional (BX61; Olympus) or a confocal (FV1000; Olympus) microscope.

Cell counting strategy. The confocal microscope was used to acquire 30 images from random consecutive fields of each glass coverslip (each sample). Ten images were randomly selected and used for the quantification of total number $\left(\mathrm{DAPI}^{+}\right.$cells), single- or double-positive cells using the Olympus Fluoview FV1000 software (Olympus). The number of double-positive cells was normalized to the number of $\mathrm{TTR}^{+}$cells (for CP epithelial cells), GFAP ${ }^{+}$cells (for astrocytes) or $\mathrm{MitoT}^{+}$(mitochondrial marker) cells. Increased percentage of double-positive cells after treatment with $A \beta_{1-42}$ was calculated assuming $100 \%$ for the respective time-point controls.

Western blot for LCN2 and $\mathbf{A} \boldsymbol{\beta}_{\text {1-42. }}$. To assess the presence of cellular LCN2 protein, total protein was extracted from cells homogenized in suspension buffer $(0.25 \mathrm{M} \mathrm{NaCl} ; 0.05 \mathrm{M}$ Tris-HCl pH 7.6; $2 \mathrm{mM}$ EDTA pH 8.0, $10 \%$ glycerol and complete protease inhibitor cocktail, all from Sigma-Aldrich), followed by sonication for $3 \mathrm{~min}$. The homogenates were centrifuged at $4{ }^{\circ} \mathrm{C}$ for $10 \mathrm{~min}$ at 10000 r.p.m., and the pellet was discarded. Proteins were quantified using the Bio-Rad protein assay. To assess the degree of $A \beta_{1-42}$ oligomerization or the presence of LCN2 in the culture medium supernatants, the samples were concentrated by reducing the total volume of medium to about $1 / 10$ of initial 
volume, using the Thermo/Savant SpeedVac (Artisan Technology Group, Champaign, IL, USA). The same volume of culture medium $(25-40 \mu \mathrm{l})$ or total cellular protein $(10 \mu \mathrm{g})$ from each sample was boiled for $5 \mathrm{~min}$ in Laemmli buffer (4\%SDS; $0.12 \mathrm{M}$ Tris- $\mathrm{HCl}$ pH 6.8; $20 \%$ glycerol and $0.2 \mathrm{M} \mathrm{DTT}$, all from SigmaAldrich), resolved in a $10 \%$ (for LCN2) or $12 \%$ (for $A \beta_{1-42}$ ) polyacrylamide gel (SDS-PAGE) and then transferred to a nitrocellulose membrane. The membrane was stained with Ponceau S (Sigma-Aldrich) to confirm transfer efficiency. The membrane was blocked with $5 \%$ skim milk (Nestle S.A., Linda-a-Velha, Portugal) in PBS $0.1 \%$ Tween 20 (Sigma-Aldrich) and then probed with mouse anti-human $A \beta_{1-16}$ (6E10) antibody (1:1000, Covance, Madrid, Spain) or goat anti-mouse LCN2 antibody (1:500, R\&D Systems) in 2.5\% skim milk in PBS $0.1 \%$ Tween 20. Goat anti-mouse IgG-HRP (1:5000, Santa Cruz Biotechnology, Santa Cruz, CA, USA) or donkey anti-goat IgG-HRP (1:10000, Santa Cruz Biotechnology) in PBS $0.1 \%$ Tween 20 was employed as secondary antibodies for $A \beta_{1-16}$ and LCN2, respectively. The blot was developed using the Clarity Western ECL Substrate (Bio-Rad Laboratories) and exposed to X-ray film (Amersham, Uppsala, Sweden). If necessary, the membrane was also blotted with anti-mouse $\beta$-actin antibody (1:100, Santa Cruz Biotechnology) to normalize for cellular protein load. Ratio between the intensity of the bands of LCN2 and $\beta$-actin was measured using the image processing software ImageJ (Bethesda, MD, USA).

Measurement of cellular dehydrogenase activity and viability. Dehydrogenase activity of CP epithelial cells, astrocytes and neurons was measured using the CellTiter 96 AQueous One Solution Cell Proliferation Assay (Promega, Madison, WI, USA), according to manufacturer's instructions. Briefly, after the different treatments, cells were washed, first with PBS and then with DMEM, and incubated with the tetrazolium compound diluted in DMEM $(1: 5)$ for a period of $2-3 \mathrm{~h}$, at $37^{\circ} \mathrm{C}$ in a humidified atmosphere $\left(5 \% \mathrm{CO}_{2}\right)$. The degree of conversion of tetrazolium into the formazan product by viable cells is considered a surrogate marker of the cellular dehydrogenase activity. ${ }^{55}$ Following this incubation period, culture medium of each culture well was distributed in triplicates in a 96-well plate and the absorbance was read at $490 \mathrm{~nm}$. Absorbance values were divided by the number of DAPI-positive nuclei in the corresponding cell culture well, giving us a measure of the cellular metabolism of tetrazolium into formazan. To calculate the differences in dehydrogenase activity between the control and $A \beta_{1-42}$ or control and LPS groups, the normalized absorbance values obtained for the vehicle-treated cells (of each genotype) at 48 or $72 \mathrm{~h}$, were defined as $100 \%$ of dehydrogenase activity. Cell viability was assessed using the LIVE/DEAD Viability/Cytotoxicity Kit (Invitrogen), according to the manufacturer's instructions. Briefly, cells from each well were washed with PBS and incubated with $2 \mu \mathrm{M}$ of ethidium homodimer- 1 and $0.5 \mu \mathrm{M}$ of the polyanionic dye calcein in PBS for 45 min at RT, protected from light. Cells were then washed with PBS and stained with DAPI for 5 min at RT. Finally, cells were washed with PBS, fixed with $4 \%$ paraformaldehyde at RT for 20 min, washed with PBS, mounted with glass coverslips in PermaFluor mounting medium and kept at $4{ }^{\circ} \mathrm{C}$ in the dark until further use. Alive cells incorporated calcein and emitted green fluorescence $(517 \mathrm{~nm})$, whereas ethidium homodimer-1 was incorporated in the nucleus of dead cells and emitted red fluorescence $(617 \mathrm{~nm})$. The number of fluorescent live and dead cells was counted and the percentage of dead cells was determined.

Statistical analysis. Values are reported as means \pm standard error (S.E.M.). Each condition was tested at least in triplicates in each independent experiment and the number of independent experiments is specified in the legend of each Figure. Statistical significant differences between groups were determined using one-way ANOVA, followed by Tukey's multiple comparison test. Values were considered to be statistically significant for $P<0.05$ ( ${ }^{*}$ or ${ }^{\#}$ ) and $P<0.01$ ( ${ }^{* *}$ or ${ }^{\# \#}$ ).

\section{Conflict of Interest}

The authors declare no conflict of interest.

Acknowledgements. We thank Dr. Ioannis Sotiropoulos for reagents and comments. Sandro Da Mesquita and Ana Catarina Ferreira are recipients of $\mathrm{PhD}$ fellowships and Fernanda Marques is recipient of a postdoctoral fellowship by the Fundação para a Ciência e Tecnologia (FCT, Portugal)/ FEDER. This work was supported by a grant from FCT/FEDER (EXPL/NEUOSD/2196/2013).
1. Benilova I, Karran E, De Strooper B. The toxic Abeta oligomer and Alzheimer's disease: an emperor in need of clothes. Nat Neurosci 2012; 15: 349-357.

2. Liu B, Moloney A, Meehan S, Morris K, Thomas SE, Serpell LC et al. Iron promotes the toxicity of amyloid beta peptide by impeding its ordered aggregation. J Biol Chem 2011; 286: 4248-4256.

3. Wang L, Xi G, Keep RF, Hua Y. Iron enhances the neurotoxicity of amyloid beta. Transl Stroke Res 2012; 3: 107-113.

4. Crichton RR, Dexter DT, Ward RJ. Brain iron metabolism and its perturbation in neurological diseases. J Neural Transm 2011; 118: 301-314.

5. Leskovjan AC, Kretlow A, Lanzirotti A, Barrea R, Vogt S, Miller LM. Increased brain iron coincides with early plaque formation in a mouse model of Alzheimer's disease. Neuroimage 2011; 55: 32-38.

6. Rogers JT, Randall JD, Cahill CM, Eder PS, Huang X, Gunshin $\mathrm{H}$ et al. An iron-responsive element type II in the 5'-untranslated region of the Alzheimer's amyloid precursor protein transcript. J Biol Chem 2002; 277: 45518-45528.

7. Rival T, Page RM, Chandraratna DS, Sendall TJ, Ryder E, Liu B et al. Fenton chemistry and oxidative stress mediate the toxicity of the beta-amyloid peptide in a Drosophila model of Alzheimer's disease. Eur J Neurosci 2009; 29: 1335-1347.

8. Naude PJ, Nyakas C, Eiden LE, Ait-Ali D, van der Heide R, Engelborghs S et al. Lipocalin 2: novel component of proinflammatory signaling in Alzheimer's disease. FASEB J 2012; 26: 2811-2823.

9. Kjeldsen $\mathrm{L}$, Johnsen $\mathrm{AH}$, Sengelov $\mathrm{H}$, Borregaard $\mathrm{N}$. Isolation and primary structure of NGAL, a novel protein associated with human neutrophil gelatinase. J Biol Chem 1993; 268: 10425-10432.

10. Liu Q, Nilsen-Hamilton M. Identification of a new acute phase protein. J Biol Chem 1995; 270: 22565-22570.

11. Goetz DH, Holmes MA, Borregaard N, Bluhm ME, Raymond KN, Strong RK. The neutrophil lipocalin NGAL is a bacteriostatic agent that interferes with siderophoremediated iron acquisition. Mol Cell 2002; 10: 1033-1043.

12. Bao G, Clifton M, Hoette TM, Mori K, Deng SX, Qiu A et al. Iron traffics in circulation bound to a siderocalin (Ngal)-catechol complex. Nat Chem Biol 2010; 6: 602-609.

13. Devireddy LR, Hart DO, Goetz DH, Green MR. A mammalian siderophore synthesized by an enzyme with a bacterial homolog involved in enterobactin production. Cell 2010; 141: 1006-1017.

14. Devireddy LR, Gazin C, Zhu X, Green MR. A cell-surface receptor for lipocalin $24 p 3$ selectively mediates apoptosis and iron uptake. Cell 2005; 123: 1293-1305.

15. Lee S, Lee WH, Lee MS, Mori K, Suk K. Regulation by lipocalin-2 of neuronal cell death, migration, and morphology. J Neurosci Res 2012; 90: 540-550.

16. Lee S, Kim JH, Seo JW, Han HS, Lee WH, Mori K et al. Lipocalin-2 Is a chemokine inducer in the central nervous system: role of chemokine ligand 10 (CXCL10) in lipocalin-2-induced cell migration. J Biol Chem 2011; 286: 43855-43870.

17. Lee S, Park JY, Lee WH, Kim H, Park HC, Mori K et al. Lipocalin-2 is an autocrine mediator of reactive astrocytosis. J Neurosci 2009; 29: 234-249.

18. Marques F, Rodrigues AJ, Sousa JC, Coppola G, Geschwind DH, Sousa N et al. Lipocalin 2 is a choroid plexus acute-phase protein. J Cereb Blood Flow Metab 2008; 28: 450-455.

19. Marques F, Mesquita SD, Sousa JC, Coppola G, Gao F, Geschwind DH et al. Lipocalin 2 is present in the EAE brain and is modulated by natalizumab. Front Cell Neurosci 2012; 6: 33.

20. Park LC, Calingasan NY, Uchida K, Zhang H, Gibson GE. Metabolic impairment elicits brain cell type-selective changes in oxidative stress and cell death in culture. J Neurochem 2000; 74: 114-124.

21. Puthalakath H, Huang DC, O'Reilly LA, King SM, Strasser A. The proapoptotic activity of the Bcl-2 family member Bim is regulated by interaction with the dynein motor complex. Mol Cell 1999; 3: 287-296.

22. Crossgrove JS, Li GJ, Zheng W. The choroid plexus removes beta-amyloid from brain cerebrospinal fluid. Exp Biol Med (Maywood) 2005; 230: 771-776.

23. Mesquita SD, Ferreira AC, Sousa JC, Santos NC, Correia-Neves M, Sousa N et al. Modulation of iron metabolism in aging and in Alzheimer's disease: relevance of the choroid plexus. Front Cell Neurosci 2012; 6: 25.

24. Carro E, Spuch C, Trejo JL, Antequera D, Torres-Aleman I. Choroid plexus megalin is involved in neuroprotection by serum insulin-like growth factor I. J Neurosci 2005; 25: 10884-10893.

25. Furman JL, Sama DM, Gant JC, Beckett TL, Murphy MP, Bachstetter AD et al. Targeting astrocytes ameliorates neurologic changes in a mouse model of Alzheimer's disease. J Neurosci 2012; 32: 16129-16140.

26. Bi F, Huang C, Tong J, Qiu G, Huang B, Wu Q et al. Reactive astrocytes secrete Icn2 to promote neuron death. Proc Natl Acad Sci USA 2013; 110: 4069-4074.

27. Rathore KI, Berard JL, Redensek A, Chierzi S, Lopez-Vales R, Santos M et al. Lipocalin 2 plays an immunomodulatory role and has detrimental effects after spinal cord injury. J Neurosci 2011; 31: 13412-13419.

28. Jang E, Lee S, Kim JH, Seo JW, Lee WH, Mori K et al. Secreted protein lipocalin-2 promotes microglial M1 polarization. FASEB J 2013; 27: 1176-1190.

29. Busche MA, Chen X, Henning HA, Reichwald J, Staufenbiel M, Sakmann B et al. Critical role of soluble amyloid-beta for early hippocampal hyperactivity in a mouse model of Alzheimer's disease. Proc Natl Acad Sci USA 2012; 109: 8740-8745. 
30. Paratore S, Parenti R, Torrisi A, Copani A, Cicirata F, Cavallaro S. Genomic profiling of cortical neurons following exposure to beta-amyloid. Genomics 2006; 88: 468-479.

31. Mucha M, Skrzypiec AE, Schiavon E, Attwood BK, Kucerova E, Pawlak R. Lipocalin-2 controls neuronal excitability and anxiety by regulating dendritic spine formation and maturation. Proc Natl Acad Sci USA 2011; 108: 18436-18441.

32. Jang E, Kim JH, Lee S, Kim JH, Seo JW, Jin M et al. Phenotypic polarization of activated astrocytes: the critical role of lipocalin-2 in the classical inflammatory activation of astrocytes. J Immunol 2013; 191: 5204-5219.

33. Bales KR, Du Y, Dodel RC, Yan GM, Hamilton-Byrd E, Paul SM. The NF-kappaB/Re family of proteins mediates Abeta-induced neurotoxicity and glial activation. Brain Res $\mathrm{Mol}$ Brain Res 1998; 57: 63-72.

34. Hamzic N, Blomqvist A, Nilsberth C. Immune-induced expression of lipocalin-2 in brain endothelial cells: relationship with interleukin-6, cyclooxygenase-2 and the febrile response. J Neuroendocrinol 2013; 25: 271-280.

35. Marques F, Falcao AM, Sousa JC, Coppola G, Geschwind D, Sousa N et al. Altered iron metabolism is part of the choroid plexus response to peripheral inflammation. Endocrinology 2009; 150: 2822-2828.

36. Rathore $\mathrm{KI}$, Redensek A, David S. Iron homeostasis in astrocytes and microglia is differentially regulated by TNF-alpha and TGF-beta1. Glia 2012; 60: 738-750.

37. Song W, Su H, Song S, Paudel HK, Schipper HM. Over-expression of heme oxygenase-1 promotes oxidative mitochondrial damage in rat astroglia. J Cell Physiol 2006; 206: 655-663.

38. Kell DB. Iron behaving badly: inappropriate iron chelation as a major contributor to the aetiology of vascular and other progressive inflammatory and degenerative diseases. BMC Med Genomics 2009; 2: 2

39. Ewings KE, Wiggins CM, Cook SJ. Bim and the pro-survival Bcl-2 proteins: opposites attract, ERK repels. Cell Cycle 2007; 6: 2236-2240.

40. Li J, Ramenaden ER, Peng J, Koito H, Volpe JJ, Rosenberg PA. Tumor necrosis factor alpha mediates lipopolysaccharide-induced microglial toxicity to developing oligodendrocytes when astrocytes are present. J Neurosci 2008; 28: 5321-5330.

41. Biswas SC, Shi Y, Vonsattel JP, Leung CL, Troy CM, Greene LA. Bim is elevated in Alzheimer's disease neurons and is required for beta-amyloid-induced neuronal apoptosis. J Neurosci 2007; 27: 893-900.

42. Chan YR, Liu JS, Pociask DA, Zheng M, Mietzner TA, Berger T et al. Lipocalin 2 is required for pulmonary host defense against Klebsiella infection. J Immunol 2009; 182: 4947-4956.
43. Tahara K, Kim HD, Jin JJ, Maxwell JA, Li L, Fukuchi K. Role of Toll-like receptor signalling in Abeta uptake and clearance. Brain 2006; 129(Pt 11): 3006-3019.

44. Leow-Dyke S, Allen C, Denes A, Nilsson O, Maysami S, Bowie AG et al. Neuronal Toll-like receptor 4 signaling induces brain endothelial activation and neutrophil transmigration in vitro. J Neuroinflammation 2012; 9: 230

45. Abramov AY, Canevari L, Duchen MR. Beta-amyloid peptides induce mitochondrial dysfunction and oxidative stress in astrocytes and death of neurons through activation of NADPH oxidase. J Neurosci 2004; 24: 565-575.

46. Weintraub S, Wicklund AH, Salmon DP. The neuropsychological profile of Alzheimer disease. Cold Spring Harb Perspect Med 2012; 2: a006171.

47. Choi J, Lee HW, Suk K. Increased plasma levels of lipocalin 2 in mild cognitive impairment. J Neurol Sci 2011; 305: 28-33.

48. Flo TH, Smith KD, Sato S, Rodriguez DJ, Holmes MA, Strong RK et al. Lipocalin 2 mediates an innate immune response to bacterial infection by sequestrating iron. Nature 2004; 432: 917-921.

49. Marques F, Sousa JC, Coppola G, Falcao AM, Rodrigues AJ, Geschwind DH et al. Kinetic profile of the transcriptome changes induced in the choroid plexus by peripheral inflammation. J Cereb Blood Flow Metab 2009; 29: 921-932.

50. Sousa JC, Cardoso I, Marques F, Saraiva MJ, Palha JA. Transthyretin and Alzheimer's disease: where in the brain? Neurobiol Aging 2007; 28: 713-718.

51. Cerqueira SR, Silva BL, Oliveira JM, Mano JF, Sousa N, Salgado AJ et al. Multifunctionalized CMCht/PAMAM dendrimer nanoparticles modulate the cellular uptake by astrocytes and oligodendrocytes in primary cultures of glial cells. Macromol Biosci2012; 12: $591-597$

52. Oliveira TG, Chan RB, Tian H, Laredo M, Shui G, Staniszewski A et al. Phospholipase d2 ablation ameliorates Alzheimer's disease-linked synaptic dysfunction and cognitive deficits. J Neurosci 2010; 30: 16419-16428.

53. Piras S, Furfaro AL, Piccini A, Passalacqua M, Borghi R, Carminati E et al. Monomeric Abeta1-42 and receptor for advanced glycation end product: key players in neuronal differentiation. Neurobiol Aging 2014; 35: 1301-1308.

54. Rozen S, Skaletsky H. Primer3 on the WWW for general users and for biologist programmers. Methods Mol Biol 2000; 132: 365-386.

55. Dunigan DD, Waters SB, Owen TC. Aqueous soluble tetrazolium/formazan MTS as an indicator of NADH- and NADPH-dependent dehydrogenase activity. BioTechniques 1995; 19: $640-649$

Supplementary Information accompanies this paper on Cell Death and Differentiation website (http://www.nature.com/cdd) 